\title{
RAB6 GTPase is a crucial regulator of the mammary secretory function controlling STAT5 activation
}

Surya Cayre a , Marisa M. Faraldo a,b, Sabine Bardin a, Stéphanie Miserey-Lenkei a , MarieAnge Deugnier ${ }^{\mathrm{a}, \mathrm{b}^{*}}$ and Bruno Goud $\mathrm{a}^{\mathrm{a}^{*}}$

${ }^{a}$ Institut Curie, PSL Research University, Sorbonne Université, CNRS, UMR144, Paris, F75005, France

${ }^{\mathrm{b}}$ INSERM, Paris, F-75013, France

* Last co-authors

Corresponding authors: Marie-Ange Deugnier and Bruno Goud, Institut Curie, PSL Research University, CNRS, UMR 144, 26 rue d'Ulm, F-75005, Paris, France.

marie-ange.deugnier@curie.fr

bruno.goud@curie.fr

Running title: RAB6 in mammary secretory function

Key words: RAB6 GTPase, mammary gland, luminal secretory cells, STAT5, PRL signaling 


\title{
SUMMARY STATEMENT
}

This study reveals a role for the Golgi-associated RAB GTPases, RAB6A/A', in the lactogenic function of the mammary gland.

\begin{abstract}
The Golgi-associated RAB GTPases, RAB6A and RAB6A', regulate anterograde and retrograde transport pathways from and to the Golgi. In vitro, RAB6A/A' have been reported to be involved in several cellular functions, including, in addition to transport, cell division, migration, adhesion and polarity. However, their role remains poorly described in vivo, in particular in epithelial tissues. Here, we generated BlgCre; Rab $6 a^{\mathrm{F} / \mathrm{F}}$ mouse presenting a specific deletion of Rab6a in the mammary luminal secretory lineage during gestation and lactation. Rab6a loss severely impaired the differentiation, maturation and maintenance of the secretory tissue, compromising lactation. It led to a decreased activation of STAT5, a key regulator of the lactogenic process primarily governed by prolactin. Data obtained with a human mammary epithelial cell line suggested that defective STAT5 activation might originate from a perturbed transport of the prolactin receptor, altering its membrane expression and signaling cascade. Despite the major functional defects observed upon Rab6a deletion, the polarized organization of the mammary epithelial bilayer was preserved. Altogether, our data reveal a crucial role for RAB6A/A' in the lactogenic function of the mammary gland. They also suggest that the trafficking pathways controlled by RAB6A/A' depend on cell type specialization and tissue context.
\end{abstract}




\section{INTRODUCTION}

Small GTPases of the RAB family are master regulators of vesicular transport and membrane trafficking in eukaryotic cells. Through their specific intracellular localization and ability to recruit various types of effectors, RAB GTPases tightly control the molecular exchanges between cell compartments (Stenmark, 2009). This large family comprises about 70 members in human and includes four RAB6 proteins, RAB6A and its splice variant RAB6A', RAB6B and RAB6C. The ubiquitously expressed RAB6A/A' are the most abundant Golgi-associated RAB GTPases and have been reported to control anterograde and retrograde trafficking from and to the Golgi apparatus (Goud et al., 2018).

RAB6A/A' has been intensively studied in cultured cells and implicated in several cellular functions, including cell division, migration, adhesion, polarity establishment and secretory mechanisms (Miserey-Lenkei et al., 2006 and 2010; Micaroni et al., 2013; ShafaqZadah et al., 2016; Fourrière et al., 2019; Homma et al., 2019). Importantly, we recently reported that RAB6A/A' are essential for early embryonic development. RAB6A/A' null mouse embryos die at day 5.5, exhibiting defective adhesion between the epiblast layer and the visceral endoderm, with a disorganization of the basement membrane and a perturbed expression of the $\beta 1$ integrin chain in epiblast cells (Shafaq-Zadah et al., 2016).

To investigate the role of RAB6A/A' in specific tissular context, we have generated $R a b 6 a^{\mathrm{F} / \mathrm{F}}$ mice carrying a conditional null allele of Rab6a that allows the targeted deletion of RAB6A/A' (Bardin et al., 2015). Using this model, we have shown that RAB6A/A' is required for the proper maturation of melanosomes in melanocytes and that they play a key role in T lymphocyte activation (Patwardhan et al., 2017; Carpier et al., 2018).

RAB6 function in highly polarized epithelial tissues remains poorly documented yet. Mammary gland provides a unique model to study morphogenesis, epithelial tissue polarity, cell fate specification and secretory mechanisms. Its development, mainly postnatal, comprises two distinct morphogenetic events: the growth and branching of epithelial ducts during puberty and the lobulo-alveolar development during gestation (Macias and Hinck, 2012; Brisken and Atacca, 2015). At each pregnancy, under progesterone and prolactin (PRL) stimulation, the mammary epithelium undergoes proliferation and differentiation preparing it for milk secretion, its primary function. At parturition, a fall in progesterone accompanied by 
elevated PRL levels triggers secretory activation and lactation (Anderson et al., 2007). PRL and its receptor (PRLR) play a pivotal role in alveologenesis and lactation, in particular through activation of the transcription factor STAT5 (Hennighausen and Robinson, 2008).

In ducts and alveoli, the mammary epithelium comprises an outer layer of basal myoepithelial cells and an inner layer of luminal cells organized around a lumen. This bilayered structure sits on a basement membrane surrounded by stromal elements. During lactation, the secretory luminal cells produce milk components, including milk proteins, lactose and lipids, whereas the contractile myoepithelial cells serve for milk expulsion (Anderson et al., 2007; Moumen et al., 2011). Luminal cells are highly polarized, with an apical domain facing the lumen and a basolateral domain contacting adjacent luminal and myoepithelial cells. In addition, during lactation, secretory luminal cells interact with the basement membrane, myoepithelial cells forming a discontinuous layer around alveoli. Due to their specialized function and numerous interactions, luminal cells display a large set of apical and baso-lateral surface proteins (Glukhova and Streuli, 2013; Chatterjee and McCaffrey, 2014).

The mammary luminal cell population is heterogeneous, comprising hormone-sensing cells positive for estrogen and progesterone receptors (ER, PR) and cells devoid of ER/PR expression (Brisken and Ataca, 2015). The secretory lineage is largely composed of ER/PRcells. It contains distinct stem/progenitor cells that are amplified during gestation and give rise to fully functional secretory cells in the lactating gland (Rodilla et al., 2015; Bach et al., 2017). To study the role of RAB6A/A' in mammary gland development and function, we generated $\mathrm{BlgCre}$; Rab6a $a^{\mathrm{F} / \mathrm{F}}$ mice, in which Rab6a was deleted specifically in the secretory lineage via the beta-lactoglobulin (Blg) promoter, primarily active throughout pregnancy and lactation (Selbert et al., 1998; Chapman et al.,1999; Naylor et al., 2005; Molyneux et al., 2010; Romagnoli et al., 2020).

\section{RESULTS}

\section{RAB6A/A' expression is upregulated in the luminal secretory lineage during gestation}

To get insight into RAB GTPase expression in mammary luminal cells, we first analyzed their transcriptomic profiles. In the adult virgin gland, the ER/PR- luminal cell 
population, targeted by the $B l g$ promoter, can be separated from the $\mathrm{ER} / \mathrm{PR}^{+}$cell fraction using ICAM-1 expression, as described in a previous work (Di-Cicco et al., 2015). In flow cytometry, ICAM-1, combined with the epithelial-specific marker CD24, discriminates $\mathrm{CD} 24^{\text {low }} \mathrm{ICAM}^{+}$basal cells, CD24 ${ }^{\text {high }} \mathrm{ICAM} 1^{-}$luminal cells $\left(\mathrm{ER} / \mathrm{PR}^{+}\right.$, referred to as $\left.\mathrm{HR}^{+}\right)$ and $\mathrm{CD} 24^{\text {high }} \mathrm{ICAM}^{+}$luminal cells (mostly ER/PR; ; referred to as HR-) (Fig.1A; Di-Cicco et $a l ., 2015)$. Using the transcriptomic profiles of the $\mathrm{HR}^{+}\left(\mathrm{ICAM}^{-}\right)$and $\mathrm{HR}-\left(\mathrm{ICAM} 1^{+}\right.$) luminal cell subsets that we previously established (Chiche et al., 2019), we analyzed the expression levels of the 58 Rab GTPase genes present in the microarrays. Only $19 R a b$ genes were found robustly expressed in both $\mathrm{HR}^{+}$and $\mathrm{HR}^{-}$luminal cell populations (Fig. 1B). These include, in addition to Rab6a, Rabla/b, Rab2a, Rab4a, Rab5a/c, Rab7a, Rab8a/b, Rab9a, Rab10, Rab11a/b, Rab14, Rab18, Rab21, Rab24 and Rab25. HR ${ }^{+}$and HR- luminal cell populations displayed very similar Rab profiles, Rabla, Rab2a, Rab7a, Rab10 and Rab14 being the top ranked genes. Of note, they did not significantly express Rab6b (Fig. 1B), known to be mainly expressed in neuronal and neuro-endocrine cells (Opdam et al., 2000; Goud et al., 2018).

Consistent with the microarray analysis, qPCR data confirmed that similar amounts of Rab6a transcripts were detected in $\mathrm{HR}^{-}$and in $\mathrm{HR}^{+}$luminal cells isolated from virgin glands (Fig.1C). Rab6a' was also present in both luminal subsets, at level close to that of Rab6a (Fig.1C). The two variants were expressed in basal cells at similar level than in luminal cells (Fig.1C).

To further investigate Rab6a expression in the mammary epithelium, we isolated luminal and basal cells from mice at day 15 of gestation (Fig.1A), using differential expression of CD24 and $\alpha 6$ integrin chain (CD49f) as described (Visvader and Stingl, 2014). At this stage, the luminal population is largely composed of $\mathrm{HR}^{-}$cells that have been amplified upon hormonal stimulation and are committed to the secretory lineage (Macias and Hinck, 2012). Interestingly, qPCR data showed that luminal cells from pregnant mice displayed higher levels of Rab6a than those from adult virgin mice (Fig.1C). Rab6a' expression in luminal cells exhibited the same tendency than that of Rab6a (Fig.1C). Rab6a and Rab6a' levels were not significantly modulated in basal cells upon gestation (Fig.1C).

Overall, these data demonstrate that Rab6a/a' expression is upregulated during pregnancy in luminal cells only and therefore suggest an important role for RAB6A/A' in the secretory lineage. Consistently, using an antibody recognizing all RAB6 isoforms, we observed a strong RAB6 expression in the luminal secretory cells of the lactating gland (Fig.1D). As expected for a Golgi-associated protein, RAB6 was concentrated at the apical 
pole of the luminal cells.

\section{Mammary development and epithelium organization of BlgCre; $R a b 6 a^{\mathrm{F} / \mathrm{F}}$ mice are not critically affected at day 15 of pregnancy (P15)}

The Blg promoter activity has been reported to substantially increase from midpregnancy (around P10) and culminate during lactation (Selbert et al., 1998). To evaluate the role of RAB6A/A' (hereafter referred to as RAB6A) in the development of the luminal secretory lineage, we first analyzed the mammary phenotype of $\mathrm{B} \operatorname{lgCre} ; R a b 6 a^{\mathrm{F} / \mathrm{F}}$ mutant mice at P15, using $R a b 6 a^{\mathrm{F} / \mathrm{F}}$ littermates as controls. Quantitative flow cytometry analyses showed that mutant and control mammary tissues displayed similar percentages of CD24+ epithelial cells with identical luminal/basal cell ratios (Figs. S1A-B). Surface expression of $\alpha 6$ or $\beta 1$ integrin chains was not perturbed in mutant luminal and basal cells (Fig. S1A). The extent of Rab6a deletion, checked in isolated mutant luminal cells by qPCR, was estimated at $80 \%$ (Fig. S1C), in agreement with previous studies using BlgCre-mediated gene deletion (Chapman et al.,1999; Naylor et al., 2005; Romagnoli et al., 2020).

In line with the flow cytometry data, whole-mount analyses did not reveal differences between mutant and control mammary trees that displayed similar fat pad occupancy and branching patterns (Fig. S1D). Organization of the mammary bilayer, evidenced by double labeling for the luminal- and basal-specific keratins, K8 and $\mathrm{K} 5$, was not perturbed in mutant mice (Fig. S1D). As expected at this developmental stage, mutant and control mammary epithelium were actively proliferating (Fig. S1D). They both displayed typical alveolar buds with nascent cytoplasmic lipid droplets (CLD) positive for adipophilin (ADPH) (Fig. S1E), a major CLD protein whose expression is specifically induced in alveolar luminal cells around mid-pregnancy (Anderson et al., 2007; Russel et al., 2011). Percentages of PR ${ }^{+}$luminal cells were similar in mutant and control epithelium (Fig. S1F), indicating that the relative proportion of $\mathrm{HR}^{-}$and $\mathrm{HR}^{+}$luminal lineages was not affected upon Rab6a deletion.

Collectively, these data indicated that Rab6a deletion in luminal cells did not critically impact the first set of pregnancy-associated developmental events, resulting in amplification of basal and luminal cell populations, side branching and alveolar bud formation. Moreover, the bilayered organization of the mammary epithelium and expression of luminal cell markers, such as $\mathrm{K} 8, \mathrm{ADPH}, \alpha 6$ and $\beta 1$ integrin chains, were preserved upon Rab6a deletion. 


\section{BlgCre; $\boldsymbol{R} a b 6 a^{F / F}$ mice exhibit altered alveolar differentiation at late gestation}

We next analyzed the mammary phenotype of BlgCre; Rab6a $a^{\mathrm{F} / \mathrm{F}}$ mutant mice at day 18 of pregnancy (P18). This prelactational stage is characterized by well described histological changes and secretory differentiation events. These include alveolar distension with luminal space enlargement, presence of large CLDs in alveolar luminal cells and substantial milk protein expression, in particular caseins, Whey Acidic Protein (WAP) and $\alpha$-lactalbumin, an essential cofactor for milk lactose synthesis (Oakes et al., 2006; Anderson et al., 2007; Oakes et al., 2017).

Whole-mount images indicated that the mutant epithelium, although well developed, appeared less dense than the control (Fig. 2A). In line with this observation, histological analyses of hematoxylin/eosin-stained sections showed that the alveoli from mutant glands were condensed compared to those from control glands (Fig. 2B), evoking reduced amounts of secretory products. Quantification of alveolar size distribution confirmed that unlike controls, the mutant glands contained a majority of alveoli of small to medium size and almost no large alveoli (Fig. 2C). This phenotype was not associated with reduced proliferation capacities. Indeed, proliferation index was twice as high in the mutant compared to the control epithelium (Fig. 2D), indicating that RAB6A-deficient mammary glands, unlike controls, were still in an active growing phase.

Notably, hematoxylin/eosin staining revealed that alveoli from the mutant tissue displayed a poor number of CLDs (Fig. 2C). Immunofluorescent studies confirmed the presence of large ADPH-coated CLDs in alveolar luminal cells from control glands (Fig. 2E). In contrast, mutant alveolar luminal cells primarily contained small ADPH-expressing CLDs often located at the basal pole (Fig. 2E), a distribution pattern observed at P15 in both control and mutant tissues (Fig. S1E). Thus, RAB6A deficiency appeared to impair or considerably delay CLD maturation, indicating perturbed secretory differentiation events.

To further analyze the differentiation features characterizing late gestation, we performed western blotting (WB) on mammary gland extracts using an antibody against mouse milk-specific proteins, as reported (Oakes et al., 2017). The data showed that the mutant samples contained lower amounts of milk components than the controls, including $\alpha-$ lactalbumin, caseins and WAP (Fig. 2F). Efficiency of RAB6 depletion was controlled in parallel using an antibody recognizing RAB6A/A' and RAB6B (Fig. 2F and S2A). In line with the WB data, immunolocalization studies showed that in the mutant tissue, numerous 
alveoli lacked $\beta$-casein expression whereas in controls, almost all alveoli displayed a strong $\beta$ casein staining lining the lumen (Fig. 2G).

Immunodetection of lineage-specific markers showed that overall, the polarized organization of the mutant mammary epithelium was preserved at late pregnancy. In mutant as in control alveoli, K8-positive luminal cells were surrounded by basally-located myoepithelial cells expressing K5 and smooth-muscle actin (SMA) (Fig. S2B). Laminin, a major component of the basement membrane, appeared normally deposited around the alveoli of the mutant tissue (Fig. 2H). Major markers of apical and baso-lateral polarity, such as ZO1, MUC1, E-cadherin and $\beta 1$ integrin, were strongly expressed and properly localized in the mutant alveolar luminal cells (Fig. 2H and S2B-D). ZO-1 and MUC1 staining well illustrated the reduced luminal space of the condensed mutant alveoli (Fig. S2C). Flow cytometry analyses confirmed that surface expression of $\alpha 6$ and $\beta 1$ integrin chains was not perturbed in the mutant epithelium, neither in luminal nor in basal cells (Fig. S2E).

Together, the data obtained at late pregnancy revealed impaired or delayed differentiation events in $\mathrm{BlgCre}$; Rab6a $a^{\mathrm{F} / \mathrm{F}}$ mammary glands. In particular, the mutant epithelium exhibited deficient CLD maturation and decreased milk protein production, most probably accounting for the defective alveolar enlargement. This indicated an important role for RAB6A in the alveolar differentiation stage characterizing the prelactational phase. Noticeably, perturbations induced by loss of Rab6a occurred without any obvious alterations of the bilayered organization of the mammary epithelium and the apico-basal polarity of the alveolar luminal cells, suggesting functional rather structural defects.

\section{BlgCre; $\operatorname{Rab6a}^{\mathrm{F} / \mathrm{F}}$ mice display a severe lactation defect}

In primiparous control mice, at day one of lactation (L1), the lobulo-alveolar structures almost entirely occupied the mammary fat pad and the milk-producing alveoli were markedly dilated, as seen on whole-mounts and histological sections (Fig. 3A). In contrast, the mammary epithelium from $\mathrm{B} \operatorname{lgCre} ; R a b 6 a^{\mathrm{F} / \mathrm{F}}$ mutant mice showed a significant reduction in fat pad occupancy (Fig. 3A) and as observed at late gestation, the mutant tissue was devoid of large alveoli (Fig. 3A and S3A). Immunohistofluorescence studies showed that as expected, RAB6 was absent from the secretory luminal cells of BlgCre; $R a b 6 a^{\mathrm{F} / \mathrm{F}}$ mice at L1 whereas it was detected in the non-targeted basal myoepithelial cells (Fig. 3B). Alveolar luminal cells lacking RAB6 exhibited a normal distribution of GM130, a cis-Golgi marker preferentially localized at their apical pole (Fig. 3B). The bilayered organization of the mutant mammary epithelium was conserved and although poorly distended, alveoli were decorated with 
myoepithelial cells displaying a stellate shape, typical of the lactation period (Fig. 3C). Mutant as control alveoli were enveloped by a continuous basement membrane rich in laminin (Fig. 3D).

We next investigated the ability of BlgCre; Rab6a $a^{\mathrm{F} / \mathrm{F}}$ females to support growth of a first litter. Whereas almost all control dams were able to feed complete litters, eight out of the eighteen (44.5\%) mutant dams analyzed had lost pups at L1 (Fig. 3E). Non-viable newborns were found to lack milk in their stomach, suggesting inability of mutant mothers to feed normally. Beyond L1, ethical reasons led us to eliminate most of the pups nursed by mutant dams, their survival being compromised by malnourishment. At L6, only four out of the eleven (36.4\%) mutant dams examined were still able to feed pups (Fig. S3B). Two of them were analyzed and although nursing 3 and 5 pups respectively, they exhibited a deeply altered lobuloalveolar development (Fig. S3C). Moreover, their pups weighted significantly less than those nursed by control mothers (Fig. S3D).

As perturbed lobulo-alveolar development and lactation defects are known to trigger early cell death, we analyzed apoptosis rates in mutant and control mammary tissues at L1, using TUNEL assays. The data revealed that unlike controls, the RAB6A-depleted tissue sections contained numerous TUNEL-positive luminal cells (Fig. 3F). Apoptotic luminal cells were distributed throughout the mutant secretory tissue.

Collectively, these data showed that loss of Rab6a in the luminal secretory lineage severely compromised lactation and induced early cell death, in primiparous females as early as postpartum day 1 .

\section{Secretory activation is impaired at the onset of lactation in BlgCre; $\operatorname{Rab6a}^{\mathrm{F} / \mathrm{F}}$ mice}

Transition from pregnancy to lactation is marked by changes in the size and cellular distribution of the luminal CLDs that are considered as signs for a proper secretory activation (Anderson et al., 2007). ADPH staining performed in control mammary glands at L1 showed that as expected, the large CLDs visible at late pregnancy have been replaced by numerous smaller CLDs targeted to the apical surface of the luminal secretory cells (Fig. 4A). Unlike controls, mutant luminal cells displayed CLDs of various size, including large ones that were stored in the cytosol (Fig. 4A). These data strongly suggest a failure in secretory activation in RAB6A-depleted alveolar luminal cells.

As observed at late gestation, WB analysis at L1 showed that compared to control, the mutant mammary tissue contained lower amounts of milk proteins (Fig. 4B). Blotting with a specific anti- $\beta$-casein antibody confirmed the reduced amount of this milk protein in the 
RAB6A-depleted tissue samples analyzed (Fig. 4C). Immunolocalization studies showed that alveolar luminal cells from the control tissue homogeneously displayed $\beta$-casein at their apical pole. In contrast, mutant alveolar luminal cells either expressed $\beta$-casein at low level or exhibited a poorly polarized distribution pattern (Fig. 4D)

In addition to proteins and lipids, lactose is an essential milk component. Its massive synthesis from glucose during lactation is accompanied by the upregulated expression of the glucose transporter, GLUT1, at the baso-lateral membrane of alveolar luminal cells (Boxer et al., 2006; Anderson et al., 2007). WB analysis at L1 revealed a reduced amount of GLUT1 in the RAB6A-depleted mammary samples compared to the controls (Fig. 4E). As expected, GLUT1 was homogeneously expressed in the control tissue and sharply localized at the basolateral membrane of the alveolar luminal cells (Fig. 4F). In contrast, GLUT1 expression in mutant alveolar luminal cells was heterogeneous, with a frequent intracellular accumulation (Fig. 4F). Other polarity markers, including baso-lateral (E-cadherin, $\beta 1$ integrin) and apical (ZO-1, MUC1) markers, appeared normally distributed in RAB6A-depleted luminal cells (Fig. S4A-C).

Collectively, our data revealed a postpartum failure in secretory activation of alveolar luminal cells. The reduced milk protein production, CLD retention and decreased GLUT1 expression suggest that milk amount and composition might be both affected in the absence of RAB6A, compromising pup growth and viability.

\section{Rab6a loss in alveolar luminal cells affects RAB18 expression}

As described above, alveolar luminal cells from BlgCre; $R a b 6 a^{\mathrm{F} / \mathrm{F}}$ females display deficient CLD maturation and apical targeting (Figs. 2E and 4A). RAB18 has been reported to control CLD growth and secretion in various lipogenic cell types (Xu et al., 2018; Dejgaard and Presley, 2019). Consistently, RAB18 belongs to the RAB GTPases highly expressed in mammary luminal cells (Fig. 1B). We thus examined whether Rab6a loss affected RAB18 expression. Using $\mathrm{WB}$, we found that RAB18 amounts were significantly decreased in the protein extracts from P18 and L1 mutant glands, compared to controls (Fig. 5A). Noticeably, the amount of other abundantly expressed RAB GTPases (RAB5, RAB8 and RAB11) was not significantly altered in the mutant samples, indicating that Rab6a loss had a particular impact on RAB18 (Fig. 5B).

In addition, using qPCR, we found that Rab6a-deleted and control mammary glands displayed similar low levels of Rab6b at L1 (Fig. 5C). These data showed that Rab6b remained poorly expressed at the onset of lactation and was not significantly affected upon 
Rab6a deletion.

\section{Rab6a loss in alveolar luminal cells leads to diminished STAT5 activation}

The transcription factor, STAT5, plays a key role in secretory differentiation and activation of the alveolar epithelium, in particular downstream of prolactin receptor (PRLR) binding to PRL (Hennighausen and Robinson, 2008). To gain mechanistic insight into the defects observed in $\mathrm{BlgCre}$; Rab6a $a^{\mathrm{F} / \mathrm{F}}$ mammary glands, we analyzed levels of the activated phosphorylated form of STAT5 (pSTAT5) in the protein extracts obtained at P18 and L1. WB data showed that compared to controls, mutant samples displayed a marked decrease in the ratios between pSTAT5 and total STAT5 amounts, indicating a reduced STAT5 activation upon Rab6a deletion (Fig. 6A). Expression of ELF5, a transcription factor controlling alveolar luminal cell maturation downstream of PRL signaling together with STAT5 (Lee and Ormandy 2012), was also diminished in mutant samples at L1 (Fig. S4D). On the other hand, similar levels of phosphorylated focal adhesion kinase (pFAK) were observed in mutant and controls samples at L1 (Fig. S4D). This indicated that integrin signaling, known to cooperate with PRL signaling for optimal STAT5 activation (Akhtar et al., 2009), was not critically affected upon Rab6a deletion.

To investigate the possible molecular mechanisms underlying the reduced STAT5 activation observed upon Rab6a deletion, we took advantage of T47-D, a human breast cancer-derived cell line commonly used for studying PRL-induced signaling events (Johnson et al., 2010; Baker et al., 2016; Oakes et al., 2017). RAB6A depletion was achieved using siRNAs targeting Rab6a/a' variants, as reported (Patwardhan et al., 2017). WB analysis of protein extracts showed that siRAB6A T47-D cells contained half of the RAB6 amount found in siCtrl T47-D cells (Fig. 6B and S4E). STAT5 being rapidly activated upon PRL binding, we analyzed T47-D cell response after 5, 15 and 45 min of PRL stimulation. Notably, at each time points, we observed a marked decrease in the pSTAT5/STAT5 ratios in RAB6Adepleted T47-D cells compared to non-depleted cells (Fig. 6B). To examine at which level PRL signaling was affected in this model, we analyzed PRLR expression using an antibody recognizing PRLR extracellular domain. Data from WB showed that RAB6A-depleted T47-D cells contained about half less PRLR than non-depleted cells and that the decreased PRLR amount persisted throughout PRL stimulation (Fig. 6C). Immunofluorescence studies indicated that RAB6A-depleted T47-D cells displayed less PRLR at their plasma membrane than non-depleted cells (Fig. 6D). 
Overall, the results obtained with the mammary tissue and the T47-D cell line revealed that RAB6A depletion led to diminished STAT5 activation. In addition, they suggested that this defect probably occurred through an altered expression of PRLR at the cell surface, resulting in decreased PRL-induced signaling events.

\section{DISCUSSION}

Our in vivo study uncovers a role for RAB6A in the differentiation and maturation of the luminal secretory lineage. Loss of Rab6a severely compromised the lactational function of the gland and the maintenance of the secretory tissue. It led to a decreased activation of STAT5, a key downstream effector of PRL-induced lactational processes. Data obtained with the PRL-responding human mammary cell line, T47-D, showed that loss of Rab6a led to decreased expression of PRLR, suggesting a perturbed transport of PRLR altering its surface expression and consequently its signaling cascade. These defects might largely account for the mammary phenotype observed in BlgCre; $R a b 6 a^{\mathrm{F} / \mathrm{F}}$ females. Noticeably, despite the major functional deficiency of the RAB6A-depleted alveolar luminal cells, the polarized organization of the mammary bilayer was preserved in vivo.

The luminal secretory lineage expresses a panel of $R a b$ transcripts, including

\section{Rab6a and Rab6a'}

Analysis of gene expression data revealed that the secretory lineage expresses a panel of Rab transcripts. These include the Rab6a and Rab6a' variants whose expression increased during pregnancy. In contrast, Rab6b remains poorly detectable in the secretory lineage in virgin as in the lactating gland. Rab genes encoding others "bona fide" Golgi-associated RAB GTPases, such as Rab19, Rab30, Rab33b, Rab34, Rab36 and Rab39b (Goud et al., 2018), were absent from the secretory lineage, at least in virgin mice. Rab transcripts of GTPases involved in pre- and cis-Golgi (Rabla/b, Rab2a, Rab18) as well as in late Golgi/TGN and post-Golgi (Rab7, Rab8, Rab10, Rab1la, Rab14) trafficking pathways were found significantly expressed in the secretory lineage.

\section{Loss of Rab6a in the secretory lineage has no major impact on mammary} morphogenesis during gestation

To delete Rab6a in the secretory lineage we used the Blg promoter, known to be specifically active in the $\mathrm{HR}^{-}$luminal progenitors and their secretory progeny from mid- 
pregnancy. This promoter is inactive in the basal and $\mathrm{HR}^{+}$luminal cell lineages, throughout mammary development (Selbert et al., 1998; Chapman et al., 1999; Naylor et al., 2005; Molyneux et al., 2010; Di-Cicco et al., 2015; Romagnoli et al., 2020). The mammary epithelium expands massively till late pregnancy. During this morphogenetic period, the HRluminal and basal progenitors are amplified essentially through progesterone and local paracrine mediators secreted by the hormone-responsive $\mathrm{HR}^{+}$cells (Fata et al., 2000; AsselinLabat et al., 2010; Brisken and Ataca, 2015; Yu et al., 2016). Whole mount and flow cytometry analyses did not reveal any severe underdevelopment of $\mathrm{BlgCre}$; $R a b 6 a^{\mathrm{F} / \mathrm{F}}$ mammary glands or perturbation of the luminal-to-basal cell balance, till late gestation. This indicated that basal and luminal progenitors have proliferated actively upon Rab6a deletion. Interestingly, unlike the control, the mutant epithelium was still actively proliferating at late gestation (P18), suggesting that loss of Rab6a may lead to a delayed mammary development possibly associated with an accumulation of $\mathrm{HR}^{-}$luminal progenitors and perturbed differentiation events.

\section{RAB6A plays a crucial role in the differentiation, activation and maintenance of} the luminal secretory cells

The major defects induced by loss of Rab6a clearly appeared at late gestation during the prelactogenic differentiation period and postpartum with the secretory activation. This led to a lactation deficiency in primiparous females, revealing a crucial role for RAB6A in the mammary gland function.

Mammary glands from numerous transgenic models showing deficiency in milk protein and lipid production display poor alveolar distension associated to defective alveolar luminal cell maturation (Naylor et al., 2005; Li et al., 2005; Russel et al., 2011; Morales et al., 2012; Akhtar et al., 2016). This phenotype was observed in BlgCre; $R a b 6 a^{\mathrm{F} / \mathrm{F}}$ at $\mathrm{P} 18$ and L1. Several aspects of the luminal secretory cell maturation were perturbed, in particular the global production of milk proteins, the expansion of CLDs and their apical targeting, and the baso-lateral expression of the glucose transporter, GLUT1. Conceivably, these perturbations altered both milk quantity and composition, compromising pup survival.

Loss of Rab6a led to a precocious luminal cell death as early as postpartum, showing that RAB6A is essential for the maintenance of the secretory tissue. The precise mechanisms remain to be determined however, it is known that the secretory differentiation and activation steps are critical to trigger and maintain the lactational process (Fata et al., 2000; Vorbach et al., 2002; Cui et al., 2004; Anderson et al., 2007; Russel et al., 2011). When these steps are 
compromised, luminal cells enter into apoptosis, a physiological process that normally occurs after weaning and leads to mammary gland involution (Watson and Kreuzaler, 2011).

\section{Loss of Rab6a does not critically affect the polarized organization of the} mammary bilayer

Loss of RAB6A during mouse embryogenesis and in migratory cell models has been reported to severely alter laminin and/or $\beta 1$ integrin expression, perturbing cell adhesion and migration (Shafaq-Zadah et al., 2016). In MDCK cells, a model presenting an apico-basal polarity in 3D cultures, RAB6A/B knock-out (RAB6-KO) strongly inhibited the secretion of soluble cargos, including laminin, whereas it mildly impaired that of transmembrane proteins (Homma et al., 2019). Of note, despite their failure in laminin secretion, RAB6-KO MDCK cells were able to form polarized cysts in $3 \mathrm{D}$ cultures.

We did not detect any obvious perturbation of laminin deposition in the mammary epithelium from BlgCre; Rab6a $a^{\mathrm{F} / \mathrm{F}}$ females, at late gestation as during lactation. In the mammary bilayer, basal myoepithelial cells rather than luminal cells express a wide range of genes coding for extracellular matrix proteins (Kendrick et al., 2008; Lim et al., 2010). It is therefore considered that basal cells, together with the surrounding stromal cells, produce most of the basement membrane components of the mammary epithelium (Moumen et al., 2011; Glukhova and Streuli, 2013).

Although less enriched in integrins than basal cells, luminal cells display several integrin chains, including $\alpha 6$ and $\beta 1$ chains (Glukhova and Streuli, 2013; Romagnoli et al., 2019 and 2020). Our data did not reveal notable perturbations neither in $\alpha 6$ and $\beta 1$ chain expression nor in FAK activation in RAB6A-deficient luminal cells. Consistently, the mammary phenotype of $\mathrm{BlgCre} ; R a b 6 a^{\mathrm{F} / \mathrm{F}}$ females did not phenocopy that observed in $\mathrm{BlgCre} ; \operatorname{Itgbl}^{\mathrm{F} / \mathrm{F}}$, BlgCre; Itga3;Itga6 $6^{\mathrm{F} / \mathrm{F}}$ and BlgCre; Ilk $k^{\mathrm{F} / \mathrm{F}}$ mice (Naylor et al., 2005; Akhtar and Streuli, 2013; Romagnoli et al., 2020). In these models, during lactation, alveoli displayed luminal cell clusters protruding into the lumen, a phenotype absent upon Rab6a deletion.

Several essential markers of the apico-basal polarity, such as E-Cadherin, MUC1 and ZO-1, appeared properly addressed to the cell surface of RAB6A-deficient alveolar luminal cells. On the other hand, GM130 immunolabelling did not reveal mis-localization of the Golgi, a characteristic observed in BlgCre; Itgbl ${ }^{\mathrm{F} / \mathrm{F}}, \mathrm{BlgCre} ; \operatorname{Itg} a 3 ; \operatorname{Itg} a 6^{\mathrm{F} / \mathrm{F}}$ and $\mathrm{BlgCre} ; \operatorname{Ilk}^{\mathrm{F} / \mathrm{F}}$ alveolar luminal cells that displayed perturbed apico-basal polarity (Akhtar and Streuli, 2013; Romagnoli et al., 2020). 
Potentially, other RAB proteins, highly expressed in the luminal secretory cells, could participate in maintaining apico-basal polarity features, in particular RAB8, a RAB GTPase implicated in the same post-Golgi transport pathways than RAB6A (Goud and Akhmanova, 2012). In addition, although expressed at very low level in the mammary tissue, RAB6B could have some compensatory function in the absence of RAB6A, as reported for RAB6-KO MDCK cells (Homma et al., 2019).

\section{Loss of Rab6a led to a decreased activation of STAT5 in the secretory tissue}

STAT5 is a key transcription factor controlling the mammary lobulo-alveolar development and the lactogenic function of the secretory lineage. Its activation level is strictly regulated in luminal cells: it gradually increases from mid- to late gestation and remains high throughout lactation (Hennighausen and Robinson, 2008; Hughes and Watson, 2012). Noticeably, we observed a decreased STAT5 activation in BlgCre; Rab6a ${ }^{\mathrm{F} / \mathrm{F}}$ mammary glands at P18 and L1.

Hennighausen and coll. have shown that STAT5 controls, directly or indirectly, the expression of multiple milk protein genes and regulatory molecules involved in the lactation process (Yamagi et al., 2013). These include, in addition to the $\beta$-casein and Wap genes, Adph required for CLD maturation in the mammary tissue and Rab18 implicated in CLD maturation and transport in lipogenic cells (Russel et al., 2011; Dejgaard and Presley, 2019). STAT5 also controls lactose production by inducing the expression of $\alpha$-lactalbumin and numerous members of the solute carrier family, such as Slc2al encoding GLUT1 (Yamagi et $a l ., 2013)$. In addition, perturbation of STAT5 activation negatively impacts the expression of ELF5, a transcription factor cooperating with STAT5 in the specification of the secretory lineage (Lee and Ormandy, 2012; Yamagi et al., 2013). Milk proteins, ELF5, ADPH, GLUT1 and $\mathrm{RAB} 18$ were found to display reduced or altered expression in $\mathrm{BlgCre} ; \mathrm{Rab} 6 a^{\mathrm{F} / \mathrm{F}}$ mammary glands at P18 and/or L1, indicating that deregulated STAT5 activation might largely account for the perturbed function of the RAB6A-deficient secretory tissue.

\section{Loss of Rab6a affects PRLR expression and its downstream STAT5 signaling}

STAT5 is predominantly activated by PRL, a pituitary hormone that plays a major role during the pre-lactogenic and lactation periods (Hennighausen and Robinson, 2008; Hughes and Watson, 2012). Therefore, the decreased STAT5 activation observed at these stages in the mammary tissue from BlgCre; $R a b 6 a^{\mathrm{F} / \mathrm{F}}$ females strongly evokes perturbation in the PRL/PRLR signaling events. 
Studies on PRLR localization in the mouse mammary gland have been hampered by the lack of antibodies. To circumvent this difficulty, we used the well-characterized PRLresponding human T47-D cells (Johnson et al., 2010; Baker et al., 2016; Oakes et al., 2017). Using siRNAs, we found that RAB6A depletion in this model resulted in decreased PRLR amount and surface expression and in reduced STAT5 activation downstream of PRL action. RAB6A plays a role in all steps of post-Golgi secretion (Goud and Akhmanova, 2012; Fourrière et al., 2019). Loss of RAB6A might thus perturb PRLR transport at different levels from Golgi to the plasma membrane, affecting its surface expression and thereby PRLinduced signaling events. Whether perturbation of intracellular PRLR transport leads to PRLR delivery to lysosomes for degradation, as reported for unsecreted cargos in RAB6-KO MDCK cells (Homma et al., 2019), remains to be determined.

Our study reveals for the first time a role for RAB6A in the lactogenic function of the mammary luminal secretory lineage and suggests that RAB6A controls STAT5 activation by regulating PRLR surface expression. The level of PRLR expressed by mammary luminal cells is known to be critical for proper alveolar development and lactation, as observed in a mouse model containing a single Prlr functional allele and displaying haploinsufficiency (Ormandy et al., 1997; Hennighausen and Robinson, 2008). In addition, high levels of STAT5 activation are required for luminal secretory cells to proceed through a full differentiation program (Yamagi et al., 2013).

RAB6A has been implicated in matrix protein secretion, cell-matrix interactions and cell polarity in different models (Shafaq-Zadah et al., 2016; Fourrière et al., 2019; Homma et $a l ., 2019)$. In contrast, our data indicate that loss of Rab6a in the luminal secretory lineage had no major impact on the structure of the mammary tissue. RAB6A function therefore appears to depend on cell type specialization and tissue context. Conceivably, in polarized tissues, distinct polarity features -apico-basal, front-rear and dual- might influence RAB6Adependent intracellular trafficking pathways. 


\section{MATERIALS AND METHODS}

\section{Mouse strains and transgenic mice}

BlgCre transgenic mice, expressing the Cre recombinase under the control of the $\mathrm{Blg}$ promoter, were purchased from The Jackson Laboratory. Rab6a $a^{\mathrm{F} / \mathrm{F}}$ mice have been previously characterized (Bardin et al., 2015). The care and use of animals were conducted in accordance with the European and National Regulation for the Protection of Vertebrate Animals used for Experimental and other Scientific Purposes (Facility license C750517/18).

\section{Dissociation of mouse mammary glands and flow cytometry analysis}

Single cells were prepared from a pool of thoracic and inguinal mammary glands harvested from adult females (12-week-old virgin or 15- and 18-day-pregnant), as described in detail elsewhere (Di-Cicco et al., 2015). Briefly, minced tissues were transferred to a digestion solution containing $3 \mathrm{mg} / \mathrm{mL}$ collagenase (Roche), 100 units $/ \mathrm{mL}$ hyaluronidase (Sigma-Aldrich) in CO2-independent medium (Gibco Life Technologies) completed with 5\% fetal bovine serum (FBS, Lonza) and 2mM L-glutamine (Sigma-Aldrich), and incubated for $90 \mathrm{~min}$ at $37^{\circ} \mathrm{C}$ with shaking. Pellets of digested samples were centrifuged and successively treated at $37^{\circ} \mathrm{C}$ with solutions of $0.25 \%$ trypsin (Life Technologies) $/ 0.1 \%$ versen (Biochrom) for $1 \mathrm{~min}, 5 \mathrm{mg} / \mathrm{ml}$ dispase II (Roche)/ 0.1mg/mL DNAseI (Sigma-Aldrich) for $5 \mathrm{~min}$. Pellets were treated with a cold ammonium chloride solution (Stem Cell Technologies) and filtered through a nylon mesh cell strainer with $40 \mu \mathrm{m}$ pores (Fisher Scientific) before immunolabeling.

Freshly isolated mammary cells were incubated at $4^{\circ} \mathrm{C}$ for $20 \mathrm{~min}$ with the following antibodies from Biolegend: anti-CD24-BViolet421 (clone M1/69; \#101826; 1/50), antiCD49f-PeCy7 (clone GoH3; \#313622; 1/50), anti-CD29-PeCy7 (clone HMß1-1; \#102222; 1/100), anti-CD45-APC (clone 30-F11; \#103112; 1/100), anti-CD31-APC (clone MEC13.3; \#102510; 1/100), anti-CD54-PE (clone YN1/1.7.4; \#116107; 1/50). Labeled cells were analyzed and sorted out using a MoFlo Astrios cell sorter (Beckman Coulter). Data were analyzed using FlowJo software. Sorted cell population purity was at least 95\%.

\section{Microarray data analysis of $R a b$ expression}

Global gene expression analysis was performed with total RNA extracted from luminal cell populations isolated by flow cytometry as previously reported (Chiche et al., 2019). Samples were hybridized on Affymetrix GeneChip Mouse Genome 2.1ST arrays. 
Hierarchical clustering was performed using hclust (R) with Euclidean distance and Ward agglomeration method. GTPase genes were classified according to their expression level that was considered as significant if $>7$.

\section{Whole-mount analyses and histology}

Dissected mammary fat pads were spread onto glass slides, fixed in Methacarn (1/3/6 mixture of acetic acid/chloroform/methanol) overnight at room temperature and stained with carmine alum (Stem Cell Technologies), or fixed in $4 \%$ paraformaldehyde overnight at $4{ }^{\circ} \mathrm{C}$, as described elsewhere (Bresson et al., 2018). For histological analyses, fixed glands were embedded in paraffin, and $7 \mu \mathrm{m}$-thick sections were cut, dewaxed and stain with hematoxylineosin. Image acquisition was performed using Nikon Eclipse 90i Upright microscope. ImageJ software (NIH) was used to quantify alveolar size.

Frozen sections ( 5 or $8 \mu \mathrm{m}$-thick) were obtained after embedding mammary glands into Tissue-Tek (Sakura), using a Leica Cryostat.

For RAB6 immunodetection, mammary glands were fixed in 4\% paraformaldehyde overnight at $4^{\circ} \mathrm{C}$, and after incubation time in sucrose solutions were embedded into TissueTek (Sakura) before freezing.

\section{Immunohistofluorescence labeling}

Paraffin sections were dewaxed, processed for acidic antigen retrieval, incubated overnight at $4{ }^{\circ} \mathrm{C}$ with primary antibodies, and then at room temperature with secondary antibodies for $2 \mathrm{~h}$.

Frozen sections fixed with $4 \%$ paraformaldehyde or acetone were incubated with antibodies as paraffin sections.

The following primary antibodies were used: anti-K5 and anti-K8 (Biolegend; \#905501; 1/1000 and \#904801; 1/100, respectively), anti-aSMA (Sigma Aldrich; \#A2547; 1/200), anti-PR (Santa Cruz; \#sc-7208; 1/200), anti-Ki67 (ThermoFisher Scientific; \#MA514520; 1/100), anti-pan-laminin (Abcam; \#ab11575; 1/100), anti-ZO-1 (Thermo Scientific; \#61-7300; 1/200), anti-MUC1 (Abcam; \#ab37435; 1/200), anti-E-cadherin ECCD-2 (Life Technology; \#13-1900; 1/200), anti-adipophilin (Progen; \#GP40; 1/100), anti-GLUT1 (Abcam; \#40084; 1/50), anti- $\beta 1$ integrin (Millipore; MAB1997; 1/100), anti-GM130 (BD Biosciences; \#610823; 1/100), anti-RAB6 (Santa Cruz; \#sc-310; 1/100). The anti-mouse $\beta$ casein was designed by Covalab. 
Alexafluor-488 or Cy3 conjugated secondary antibodies were from Jackson ImmunoResearch Laboratories. Immunostained tissue sections were mounted in Prolong Gold antifade reagent with DAPI (Invitrogen, Life Technologies).

Image acquisition was performed using either a Leica DM 6000B microscope (Wetzlar, Germany) equiped with MetaMorph software, Nikon Confocal A1R microscope 60× CFI Plan oil objective (Apo VC/NA 1.4/WD 0.13), or an Inverted Laser Scanning Confocal LSM880NLO/Mai Tai Laser (Zeiss) with an Airyscan module (63x/1,4 OIL DICII PL APO (420782-9900)).

\section{TUNEL assay}

For cell death analysis, glands were fixed in 4\% paraformaldehyde in PBS, $\mathrm{pH} 7.5$, $\mathrm{O} / \mathrm{N}$ at $4^{\circ} \mathrm{C}$. Dewaxed paraffin sections were analyzed for TdT digoxygenin nick-end labeling with Apoptag Plus (Sigma Aldrich) following manufacturer's instructions. Methyl green was used as counterstaining. Image acquisition was performed using a Leica DM RBE optic microscope (Leica Microsystems $\mathrm{GmbH}$, Allemagne) and number of apoptotic cells per field was count using ImageJ software.

\section{RNA extraction and RT-qPCR}

RNA was isolated from whole mammary glands using Trizol reagent (Life Technologies) and further purified on a cleanup column (Qiagen). RNeasy Microkit was used for RNA extraction from isolated mammary cells, as described (Di-Cicco et al., 2015; Chiche et al., 2019). To avoid eventual DNA contamination, purified RNA was treated with DNAse (Qiagen). RNAs were reverse-transcribed using MMLV H(-) Point reverse transcriptase (Promega). Quantitative PCR was performed using the QuantiNova SYBR Green PCR Kit (Qiagen) on a LightCycler 480 real-time PCR system (Roche). The values obtained were normalized to Gapdh levels. The primers used for RT-qPCR analysis were purchased from SABiosciences/Qiagen or designed using Oligo 6.8 software (Molecular biology Insights) and synthesized by Sigma Aldrich. Primers for Rab6a, Rab6a' and Rab6b used in this study are listed in Table S1.

\section{T47-D cell culture and RAB6A knockdown by siRNA}

The human mammary epithelial cell line, T47-D, was maintained at $5 \% \mathrm{CO} 2$ in a $37^{\circ} \mathrm{C}$ incubator and grown in a phenol red free-RPMI 1640 medium containing 10\% FBS and $5 \mu \mathrm{g} / \mathrm{mL}$ insulin, as described (Baker et al., 2016). 
For siRNAs knockdown experiments, cells were transfected the day after their seeding with siRNA controls (siLuciferase) or specific siRAB6A/A' (50nM final concentration) in Lullaby reagent (OZ Biosciences). A second transfection was performed 24 hours after the first one. Experiments were conducted $72 \mathrm{~h}$ after the last transfection.

24 hours before PRL treatment, cells were washed in PBS and medium was replaced by a serum-free medium. Cells were treated with human PRL (Sigma, \#L4021) at 250ng/mL for 5,15 and $45 \mathrm{~min}$ at $37^{\circ} \mathrm{C}$ in a medium supplemented with $5 \mu \mathrm{g} / \mathrm{mL}$ insulin and $1 \mu \mathrm{M}$ dexamethasone, as described (Baker et al., 2016).

Immunofluorescence staining of PRLR (anti-PRLR, Invitrogen; \#35-9200; 1/200). and RAB6 (AC306, produced and purified in B. Goud's lab; 1/1000) were performed after fixing the cells with $4 \%$ paraformaldehyde and mild permeabilization with $0.2 \%$ saponin.

\section{Western blot analysis}

Mammary tissue samples were homogenized in RIPA extraction buffer $(0.1 \%$ SDS, 276mM NaCl, 40mM Tris pH7.5, 2\% NP-40, 4mM EDTA, 20\% glycerol, 1X proteases inhibitors) following further incubation during $20 \mathrm{~min}$ at $4^{\circ} \mathrm{C}$ in a rotation wheel. After centrifugation at $12000 \mathrm{rpm}$ during $15 \mathrm{~min}$ at $4^{\circ} \mathrm{C}$, supernatants containing extracted proteins were recovered and BCA Protein assay kit from Pierce (\#23225) was used to estimate protein concentration. $40 \mu \mathrm{g}$ of protein extracts where boiled for $5 \mathrm{~min}$ in Laemmli buffer before migration. Cell pellets were resuspended in $1 \mathrm{x}$ Laemmli buffer, vortexed and boiled for 5 min. Samples were run on NuPAGE Novex 4-12\% Bis Tris gels (Life Technologies/Invitrogen) and transferred onto nitrocellulose. Membranes were incubated with 5\% BSA in TBS containing 0.1\% Tween 20 (TBST) for 1 hour at room temperature and with primary antibodies overnight at $4^{\circ} \mathrm{C}$.

The following primary antibodies were used on mouse cell-derived lysates: anti-mouse milk proteins (Accurate Chemical; YNRMMSP; 1/2000), anti-mouse $\beta$-casein (a kind gift from C. Streuli, Manchester University), anti-RAB6 (AC306, produced and purified in B. Goud's lab; 1/2000), anti-RAB5 (Cell Signaling Technology, CST; \#3547S; 1/1000), antiRAB8 (BD Biosciences; \#610844; 1/1000), anti-RAB11 (BD Biosciences; \#610656; 1/1000), anti RAB18 (Sigma; \#SAB4200173; 1/1000), anti-GLUT1 (Abcam; \#40084; 1/500), antiELF5 (Santa Cruz; sc-9645; 1/500), anti-STAT5 (Santa Cruz; \#sc-1081; 1/10000), antipSTAT5-Tyr694 (CST; \#9359; 1/1000), anti-pFAK-Tyr397 (CST; \#3283S; 1/750), anti-FAK (CST; \#3285; 1/1000). T47-D cell lysates were probed using anti-RAB6 (AC306, produced and purified in B. Goud's lab; 1/2000), anti-STAT5 (BD Biosciences; \#610191; 1/1000), anti- 
pSTAT5-Tyr694 (CST; \#9359; 1/1000) and anti-PRLR (Invitrogen; \#35-9200; 1/500).

Secondary antibodies coupled to horseradish peroxidase were from Jackson ImmunoResearch Laboratories. Detection was performed by chemiluminescence (Super signal West Pico+ or Femto, ThermoScientific). Quantitative analysis was performed with ImageLab.

\section{Statistical analysis}

p-values were determined using Student $t$-test with two-tailed distribution and Welch's correction, using the GraphPad prismv6 software. When specified, a Pearson's Chi-square test was applied.

\section{ACKNOWLEDGMENTS}

We are grateful to the personnel of the Animal facility (Céline Daviaud, Paul Bureau) and the Flow Cytometry Core facility (Annick Viguier, Sophie Grondin, Zosia Maciorowski, Coralie Guérin) at the Institut Curie. We greatly thank Amandine Di-Cicco (Institut Curie, CNRSUMR144) for expert technical assistance; Pierre de la Grange (GenoSplice, France) for generating heatmap; Lucie Sengmanivong and Vincent Fraisier from the Cell and Tissue Imaging facility (PICT-IBiSA), Institut Curie, member of the French National Research Infrastructure France-BioImaging (ANR10-INBS-04). We also greatly thank Marina Glukhova and Vincent Goffin for valuable discussions.

\section{COMPETING INTERESTS}

The authors declare no conflict of interest.

\section{FUNDING}

The work was supported by grants from the European Research Council (project 339847 MYODYN), the Institut Curie, the CNRS and the Labex Cell(n)Scale (11-LBX-0038). 


\section{REFERENCES}

Akhtar, N., Li, W., Mironov, A. and Streuli, C.H. (2016). Rac1 controls both the secretory function of the mammary gland and its remodeling for successive gestations. Dev. Cell 38, 522-535.

Akhtar, N., Marlow, R., Lambert, E., Schatzmann, F., Lowe, E.T., Cheung, J., Katz, E., Li, W., Wu, C., Dedhar, S, et al. (2009). Molecular dissection of integrin signalling proteins in the control of mammary epithelial development and differentiation. Development 136, 1019-1027.

Akhtar, N. and Streuli, C.H. (2013). An integrin-ILK-microtubule network orients cell polarity and lumen formation in glandular epithelium. Nat. Cell Biol. 15, 17-27.

Anderson, S.M., Rudolph, M.C., McManaman, J.L. and Neville, M.C. (2007). Key stages in mammary gland development. Secretory activation in the mammary gland: it's not just about milk protein synthesis! Breast Cancer Res. 9, 204.

Asselin-Labat, M.L., Vaillant, F., Sheridan, J.M., Pal, B., Wu, D., Simpson, E.R., Yasuda, H., Smyth, G.K., Martin, T.J., Lindeman, G.J. et al. (2010). Control of mammary stem cell function by steroid hormone signalling. Nature 465, 798-802.

Bach, K., Pensa, S., Grzelak, M., Hadfield, J., Adams, D.J., Marioni, J.C. and Khaled, W.T. (2017). Differentiation dynamics of mammary epithelial cells revealed by single-cell RNA sequencing. Nat. Commun. 8, 2128.

Baker, L., BeGora, M., Au Yeung, F., Feigin, M.E., Rosenberg, A.Z., Lowe, S.W., Kislinger, T. and Muthuswamy, S.K. (2016). Scribble is required for pregnancy-induced alveologenesis in the adult mammary gland. J. Cell Sci. 129, 2307-2315.

Bardin, S., Miserey-Lenkei, S., Hurbain, I., Garcia-Castillo, D., Raposo, G. and Goud, B. (2015). Phenotypic characterisation of RAB6A knockout mouse embryonic fibroblasts. Biol. Cell 107, 427-439.

Boxer, R.B., Stairs, D.B., Dugan, K.D., Notarfrancesco, K.L., Portocarrero, C.P., Keister, B.A., Belka, G.K., Cho, H., Rathmell, J.C., Thompson, C.B. et al. (2006). Isoform-specific requirement for Akt1 in the developmental regulation of cellular metabolism during lactation. Cell Metab. 4, 475-490.

Bresson, L., Faraldo, M.A., Di-Cicco, A., Quintanilla, M. Glukhova, M.A and Deugnier, M.A. (2018). Podoplanin regulates mammary stem cell function and tumorigenesis by potentiating Wnt/beta-catenin signaling. Development, 145, dev160382.

Brisken, C. and Ataca, D. (2015). Endocrine hormones and local signals during the development of the mouse mammary gland. Wiley Interdiscip. Rev. Dev. Biol. 4, 181-195. Carpier, J.M., Zucchetti, A.E., Bataille, L., Dogniaux, S., Shafaq-Zadah, M., Bardin, S., Lucchino, M., Maurin, M., Joannas, L.D., Magalhaes, J.G. et al. (2018). Rab6-dependent retrograde traffic of LAT controls immune synapse formation and T cell activation. J. Exp. Med. 215, 1245-1265.

Chapman, R.S., Lourenco, P.C., Tonner, E., Flint, D.J., Selbert, S., Takeda, K., Akira, S., Clarke, A.R. and Watson, C.J. (1999). Suppression of epithelial apoptosis and delayed mammary gland involution in mice with a conditional knockout of Stat3. Genes Dev. 13, 2604-2616.

Chatterjee, S.J. and McCaffrey, L. (2014). Emerging role of cell polarity proteins in breast cancer progression and metastasis. Breast Cancer 6, 15-27.

Chiche, A., Di-Cicco, A., Sesma-Sanz, L., Bresson, L., de la Grange, P., Glukhova, M.A., Faraldo, M.M. and Deugnier, M.A. (2019). p53 controls the plasticity of mammary luminal progenitor cells downstream of Met signaling. Breast Cancer Res. 21, 13. 
Cui, Y., Riedlinger, G., Miyoshi, K., Tang, W., Li, C., Deng, C.X., Robinson, G.W. and Hennighausen, L. (2004). Inactivation of Stat5 in mouse mammary epithelium during pregnancy reveals distinct functions in cell proliferation, survival, and differentiation. Mol. Cell. Biol. 24, 8037-8047.

Dejgaard, S.Y. and Presley, J.F. (2019). Rab18: new insights into the function of an essential protein. Cell. Mol. Life Sci. 76, 1935-1945.

Di-Cicco, A., Petit, V., Chiche, A., Bresson, L., Romagnoli, M., Orian-Rousseau, V., Vivanco, M., Medina, D., Faraldo, M.M., Glukhova, M.A. et al. (2015). Paracrine Met signaling triggers epithelial-mesenchymal transition in mammary luminal progenitors, affecting their fate. eLife 4, e06104.

Fata, J.E., Kong, Y.Y., Li, J., Sasaki, T., Irie-Sasaki, J., Moorehead, R.A., Elliott, R., Scully, S., Voura, E.B., Lacey, D.L. et al. (2000). The osteoclast differentiation factor osteoprotegerin-ligand is essential for mammary gland development. Cell 103, 41-50. Fourriere, L., Kasri, A., Gareil, N., Bardin, S., Bousquet, H., Pereira, D., Perez, F., Goud, B., Boncompain, G. and Miserey-Lenkei, S. (2019). RAB6 and microtubules restrict protein secretion to focal adhesions. J. Cell Biol. 218, 2215-2231.

Glukhova, M.A. and Streuli, C.H. (2013). How integrins control breast biology. Curr. Opin. Cell Biol. 25, 633-641.

Goud, B. and Akhmanova, A. (2012). Rab6 GTPase. In Rab GTPases and Membrane Trafficking. Bentham Science Publishers. pp 34-46.

Goud, B., Liu, S. and Storrie, B. (2018). Rab proteins as major determinants of the Golgi complex structure. Small GTPases 9, 66-75.

Hennighausen, L. and Robinson, G.W. (2008). Interpretation of cytokine signaling through the transcription factors STAT5A and STAT5B. Genes Dev. 22, 711-721.

Homma, Y., Kinoshita, R., Kuchitsu, Y., Wawro, P.S., Marubashi, S., Oguchi, M.E., Ishida, M., Fujita, N. and Fukuda, M. (2019). Comprehensive knockout analysis of the Rab family GTPases in epithelial cells. J. Cell Biol. 218, 2035-2050.

Hughes, K. and Watson, C.J. (2012). The spectrum of STAT functions in mammary gland development. JAK-STAT 1, 151-158.

Johnson, K.J., Peck, A.R., Liu, C., Tran, T.H., Utama, F.E., Sjolund, A.B., Schaber, J.D., Witkiewicz, A.K. and Rui, H. (2010). PTP1B suppresses prolactin activation of Stat5 in breast cancer cells. Am. J. Pathol. 177, 2971-2983.

Kendrick, H., Regan, J.L., Magnay, F.A., Grigoriadis, A., Mitsopoulos, C., Zvelebil, M. and Smalley, M.J. (2008). Transcriptome analysis of mammary epithelial subpopulations identifies novel determinants of lineage commitment and cell fate. BMC Genomics 9, 591. Lee, H.J. and Ormandy, C.J. (2012). Elf5, hormones and cell fate. Trends Endocrinol. Metab. 23, 292-298.

Li, N., Zhang, Y., Naylor, M.J., Schatzmann, F., Maurer, F., Wintermantel, T., Schuetz, G., Mueller, U., Streuli, C.H. and Hynes, N.E. (2005). Beta1 integrins regulate mammary gland proliferation and maintain the integrity of mammary alveoli. EMBO J. 24, 1942-1953.

Lim, E., Wu, D., Pal, B., Bouras, T., Asselin-Labat, M.L., Vaillant, F., Yagita, H., Lindeman, G.J. et al. (2010). Transcriptome analyses of mouse and human mammary cell subpopulations reveal multiple conserved genes and pathways. Breast Cancer Res. 12, R21. Macias, H. and Hinck, L. (2012). Mammary gland development. Wiley Interdiscip. Rev. Dev. Biol. 1, 533-557.

Micaroni, M., Stanley, A.C., Khromykh, T., Venturato, J., Wong, C.X., Lim, J.P., Marsh, B.J., Storrie, B., Gleeson, P.A. and Stow, J.L. (2013). Rab6a/a' are important Golgi regulators of pro-inflammatory TNF secretion in macrophages. PLoS One 8, e57034. 
Miserey-Lenkei, S., Couëdel-Courteille, A, Del Nery, E, Bardin, S, Piel, M, Racine, V., Sibarita, J.B., Perez, F, Bornens, M and Goud, B. (2006). A role for the Rab6A' GTPase in the inactivation of the Mad2-spindle checkpoint. EMBO J. 25, 278-289.

Miserey-Lenkei, S., Chalancon, G., Bardin, S., Formstecher, E., Goud, B. and Echard, A. (2010). Rab and actomyosin-dependent fission of transport vesicles at the Golgi complex. Nat. Cell Biol. 12, 645-654.

Molyneux, G., Geyer, F.C., Magnay, F.A., McCarthy, A., Kendrick, H., Natrajan, R., Mackay, A., Grigoriadis, A., Tutt, A., Ashworth, A. et al. (2010). BRCA1 basal-like breast cancers originate from luminal epithelial progenitors and not from basal stem cells. Cell Stem Cell 7, 403-417.

Morales, F.C., Hayashi, Y., van Pelt, C.S. and Georgescu, M.M. (2012). NHERF1/EBP50 controls lactation by establishing basal membrane polarity complexes with prolactin receptor. Cell Death Dis. 3, e391.

Moumen, M., Chiche, A., Cagnet, S., Petit, V., Raymond, K., Faraldo, M.M., Deugnier, M.A. and Glukhova, M.A. (2011). The mammary myoepithelial cell. Int. J. Dev. Biol. 55, 763-771.

Naylor, M.J., Li, N., Cheung, J., Lowe, E.T., Lambert, E., Marlow, R., Wang, P., Schatzmann, F., Wintermantel, T., Schuetz, G. et al. (2005). Ablation of betal integrin in mammary epithelium reveals a key role for integrin in glandular morphogenesis and differentiation. J. Cell. Biol. 171, 717-728.

Oakes, S.R., Gallego-Ortega, D., Stanford, P.M., Junankar, S., Au, W.W.Y., Kikhtyak, Z., von Korff, A., Sergio, C.M., Law, A.M.K., Castillo, L.E. et al. (2017). A mutation in the viral sensor 2'-5'-oligoadenylate synthetase 2 causes failure of lactation. PLoS Genet. 13, e1007072.

Oakes, S.R., Hilton, H.N. and Ormandy, C.J. (2006). The alveolar switch: coordinating the proliferative cues and cell fate decisions that drive the formation of lobuloalveoli from ductal epithelium. Breast Cancer Res. 8, 207.

Opdam, F.J., Echard, A., Croes, H.J., van den Hurk, J.A., van de Vorstenbosch, R.A., Ginsel, L.A., Goud, B. and Fransen, J.A. (2000). The small GTPase Rab6B, a novel Rab6 subfamily member, is cell-type specifically expressed and localised to the Golgi apparatus. $J$. Cell Sci. 113, 2725-2735.

Ormandy, C.J., Camus, A., Barra, J., Damotte, D., Lucas, B., Buteau, H., Edery, M., Brousse, N., Babinet, C., Binart, N. et al. (1997). Null mutation of the prolactin receptor gene produces multiple reproductive defects in the mouse. Genes Dev. 11, 167-178.

Patwardhan, A., Bardin, S., Miserey-Lenkei, S., Larue, L., Goud, B., Raposo, G. and Delevoye, C. (2017). Routing of the RAB6 secretory pathway towards the lysosome related organelle of melanocytes. Nat. Commun. 8, 15835.

Rodilla, V., Dasti, A., Huyghe, M., Lafkas, D., Laurent, C., Reyal, F. and Fre, S. (2015). Luminal progenitors restrict their lineage potential during mammary gland development. PLoS Biol. 13, e1002069.

Romagnoli, M., Bresson, L., Di-Cicco, A., Perez-Lanzon, M., Legoix, P., Baulande, S., de la Grange, P., De Arcangelis, A., Georges-Labouesse, E., Sonnenberg, A. et al. (2020). Laminin-binding integrins are essential for the maintenance of functional mammary secretory epithelium in lactation. Development 147, doi: 10.1242/dev.181552.

Romagnoli, M., Cagnet, S., Chiche, A., Bresson, L., Baulande, S., de la Grange, P., De Arcangelis, A., Kreft, M., Georges-Labouesse, E., Sonnenberg, A. et al. (2019).

Deciphering the Mammary Stem Cell Niche: A Role for Laminin-Binding Integrins. Stem Cell Reports 12, 831-844. 
Russell, T.D., Schaack, J., Orlicky, D.J., Palmer, C., Chang, B.H., Chan, L. and McManaman, J.L. (2011). Adipophilin regulates maturation of cytoplasmic lipid droplets and alveolae in differentiating mammary glands. J. Cell Sci. 124, 3247-3253.

Selbert, S., Bentley, D.J., Melton, D.W., Rannie, D., Lourenco, P., Watson, C.J. and Clarke, A.R. (1998). Efficient BLG-Cre mediated gene deletion in the mammary gland. Transgenic Res. 7, 387-396.

Shafaq-Zadah, M., Gomes-Santos, C.S., Bardin, S., Maiuri, P., Maurin, M., Iranzo, J., Gautreau, A., Lamaze, C., Caswell, P., Goud, B. et al. (2016). Persistent cell migration and adhesion rely on retrograde transport of beta1 integrin. Nat. Cell Biol. 18, 54-64.

Stenmark, H. (2009). Rab GTPases as coordinators of vesicle traffic. Nat. Rev. Mol. Cell. Biol. 10, 513-525.

Visvader, J.E. and Stingl, J. (2014). Mammary stem cells and the differentiation hierarchy: current status and perspectives. Genes Dev. 28, 1143-1158.

Vorbach, C., Scriven, A. and Capecchi, M.R. (2002). The housekeeping gene xanthine oxidoreductase is necessary for milk fat droplet enveloping and secretion: gene sharing in the lactating mammary gland. Genes Dev. 16, 3223-3235.

Watson, C.J. and Kreuzaler, P.A. (2011). Remodeling mechanisms of the mammary gland during involution. Int. J. Dev. Biol. 55, 757-762.

Xu, D., Li, Y., Wu, L., Zhao, D., Yu, J., Huang, T., Ferguson, C., Parton, R.G., Yang, H. and Li, P. (2018). Rab18 promotes lipid droplet (LD) growth by tethering the ER to LDs through SNARE and NRZ interactions. J. Cell Biol. 217, 975-995.

Yamaji, D., Kang, K., Robinson, G.W. and Hennighausen, L. (2013). Sequential activation of genetic programs in mouse mammary epithelium during pregnancy depends on STAT5A/B concentration. Nucleic Acids Res. 41, 1622-1636.

Yu, Q.C., Verheyen, E.M. and Zeng, Y.A. (2016). Mammary Development and Breast Cancer: A Wnt Perspective. Cancers 8, 65, doi:10.3390. 


\section{FIGURE LEGENDS}

Figure 1. Rab6 expression in mammary luminal and basal cells isolated from adult virgin and pregnant females

(A) Flow cytometry analysis of mammary cells isolated from 12-week-old virgin mice (left; V-12w) and 15-day pregnant mice (right, P15). The gated subsets within the CD24 epithelial cell pool are: CD24 ${ }^{\text {low }} \mathrm{ICAM}^{+}$basal cells $(\mathrm{Ba}), \mathrm{CD} 24^{\text {high }} \mathrm{ICAM}^{-}$and CD24 $4^{\text {high }}$ $\mathrm{ICAM}^{+}$luminal cells $\left(\mathrm{HR}^{+}\right.$and $\mathrm{HR}^{-}$, respectively) (left); CD24 ${ }^{\text {low }} \mathrm{CD} 49 \mathrm{f}^{\text {high }}$ basal cells $(\mathrm{Ba})$ and $\mathrm{CD} 24^{\text {high }} \mathrm{CD} 49 \mathrm{f}^{\text {low }}$ (right).

(B) Heat map based on microarray data (Chiche et al., 2019) showing the relative gene expression of $58 \mathrm{RAB}$ GTPases in the $\mathrm{HR}^{+}$and $\mathrm{HR}^{-}$luminal cell populations isolated from adult virgin mice as shown in A (left). Genes expressed at a significant level appear in pink to red. The heatmap includes the reference genes, Icam1, Elf5, Pgr (encoding PR) and Esr1 (encoding ER) used to characterize the luminal cell populations. Microarray data are from 7 separate sorting experiments.

(C) qPCR analysis of Rab6a and Rab6a' expression in mammary basal and luminal cells isolated from adult virgin and pregnant mice as shown in (A). Data are the mean \pm SEM of 34 separate cell preparations. ${ }^{*} \mathrm{p}=0.039$

(D) RAB6 immunolocalization in a lactating mammary gland. Actin marks basal myoepithelial cells and the apical pole of luminal cells facing the alveolar lumen (L). Nuclei are stained with DAPI. Bar, $10 \mu \mathrm{m}$.

Figure 2. Impaired alveolar luminal cell differentiation in Blg-Cre; $R a b 6 a^{\mathrm{F} / \mathrm{F}}$ females at late pregnancy (P18)

(A) Carmine-stained whole-mounts of mammary glands from control and mutant females at P18. Bar, $2.25 \mathrm{~mm}$.

(B) Views of hematoxylin/eosin-stained histological sections through control and mutant mammary glands at $\mathrm{P} 18$. Bar, $100 \mu \mathrm{m}$.

(C) Left: Enlarged views of control and mutant alveoli shown in (B) Bar, $48 \mu \mathrm{m}$. Right: compared distributions of alveolar size at P18, estimated in pixel. Data are from a pool of measurements performed on two distinct histological sections from 3 control and 3 mutant mammary glands. A total of 1450 alveoli was measured. Pearson's Chi-square test: $\mathrm{p}<0.001$ 
(D) Cell proliferation in control and mutant mammary glands at P18, estimated by Ki67 expression. Left: triple Ki67/SMA/DAPI immunofluorescent staining. SMA (smooth muscle actin) marks basal myoepithelial cells surrounding alveoli. Bar, 35 $\mu \mathrm{m}$. Right: Percentages of Ki67+ luminal cells. Data are the mean \pm SEM of counts performed on sections though 3 distinct control and mutant mammary glands. About 2000 DAPIstained nuclei were counted on each section. $* p<0.001$

(E) Immunolocalization of adipophilin and ZO-1 in control and mutant mammary tissues at P18, with enlarged views of individual alveoli. Bar, $45 \mu \mathrm{m}$.

(F) Western blots for milk proteins, RAB6 and actin (used as loading control) performed with 4 distinct control and mutant mammary gland protein extracts. Molecular size markers are shown on the left and the corresponding milk proteins, $\alpha$-lactalbumin $(\alpha \mathrm{Lac})$, whey acidic protein (WAP) and caseins (Cas) on the right. Quantification of RAB6 depletion is shown in Fig. S2A.

(G) Immunolocalization of $\beta$-casein in control and mutant mammary epithelium at P18. Arrows indicate the mutant alveoli devoid of $\beta$-casein expression. Bar, $20 \mu \mathrm{m}$.

(H) Double immunolabeling of E-cadherin and laminin $(\mathrm{ECad} / \mathrm{LN}$; bar, 15 $\mu \mathrm{m})$ in control and mutant mammary tissues at P18.

\section{Figure 3. Mammary phenotype and lactation deficiency of Blg-Cre; $R a b 6 a^{\mathrm{F} / \mathrm{F}}$ females at day 1 of lactation (L1)}

(A) Carmine-stained whole-mounts (upper panels; bar, $0.3 \mathrm{~mm}$ ) and hematoxylin/eosin-

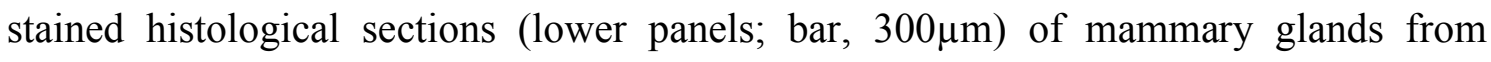
control and mutant females at L1.

(B) RAB6 and GM130 immunodetection in control and mutant alveolar luminal cells at L1. Upper panels: triple actin/RAB6/DAPI staining. Actin marks basal myoepithelial cells and the apical membrane of luminal cells. RAB6 is absent from mutant luminal cells but detected in basal myoepithelial cells. Bar, $20 \mu \mathrm{m}$. Lower panels: double GM130/DAPI staining showing similar apical Golgi distribution in control and mutant luminal cells. Bar, $12 \mu \mathrm{m}$.

(C) Immunolabeling of basal-specific (K5) and luminal-specific (K8) keratins in control and mutant mammary epithelium at L1. Right panels: enlarged views of the delineated areas. Basal myoepithelial cells display a typical stellate shape in both control and mutant samples. Bars, $40 \mu \mathrm{m}$ (left), $20 \mu \mathrm{m}$ (right). 
(D) Immunodetection of laminin (LN) in control and mutant alveoli at L1 showing similar deposition. Bar, $75 \mu \mathrm{m}$.

(E) Survival of pups nursed by control and mutant primiparous dams at L1. Litters from 24 control and 18 mutant females were analyzed. ${ }^{*} \mathrm{p}=0.05$

(F) Cell apoptosis in control and mutant mammary epithelium at L1, as revealed by TUNEL assay. Left panels: Views of sections through control and mutant glands. Methyl green was used as counterstaining. Enlarged views of the delineated areas are shown on the right. Arrows indicate TUNEL-positive cells. Bars, $75 \mu \mathrm{m}$ (left) and $55 \mu \mathrm{m}$ (right). Right panel: Number of TUNEL-positive cells per low-magnification microscopic field. Data are shown as mean \pm SEM from four control and five mutant mice. Three distinct fields per mouse were quantified. $* \mathrm{p}=0.03$

\section{Figure 4. Defective post-partum secretory activation of alveolar luminal cells in Blg-Cre;}

\section{$\operatorname{Rab6a}^{\mathrm{F} / \mathrm{F}}$ females}

(A) Immunolocalization of adipophilin in control and mutant mammary epithelium at L1. Right panels: enlarged views of the delineated areas. Adipophilin-coated CLDs are retained in the cytosol of mutant alveolar luminal cells. Bars, $30 \mu \mathrm{m}$ (left), $15 \mu \mathrm{m}$ (right).

(B) Western blots for milk proteins and actin (used as loading control) in 4 distinct control and mutant mammary gland extracts at L1. Molecular size markers are shown on the left and the corresponding milk proteins, $\alpha \mathrm{Lac}$, WAP and caseins on the right.

(C) Western blots for $\beta$-casein ( $\beta \mathrm{Cas}$ ), RAB6 and actin in 3 distinct control and mutant mammary gland extracts at L1. The lower panels show the related quantifications (mean \pm SEM) normalized on actin amounts. ${ }^{*} p=0.05$ (RAB6), ${ }^{*} p=0.026$ ( $\beta$ Cas)

(D) Immunolocalization of $\beta$-casein in control and mutant mammary epithelium at L1. Two representative fields are shown. Bar, $14 \mu \mathrm{m}$.

(E) Western blots for GLUT1 and actin in the 4 control and mutant mammary gland extracts analyzed in (B). The lower panel shows GLUT1 quantification (mean \pm SEM) normalized on actin amounts. ${ }^{*} \mathrm{p}=0.026$

(F) Immunolocalization of GLUT1 in control and mutant mammary epithelium at L1. Right panels: enlarged views of the delineated alveoli. In control, GLUT1 is sharply expressed at the baso-lateral membrane of alveolar luminal cells whereas it displays a heterogeneous and diffuse expression pattern in mutant. Bars, $20 \mu \mathrm{m}$ (left), $8 \mu \mathrm{m}$ (right). 


\section{Figure 5. RAB expression in Rab6a-deficient mammary glands}

(A) Western blots for RAB18 and actin at P18 and L1 (left panels) and quantifications (mean $\pm \mathrm{SEM}$ ) normalized on actin amounts (right panels) Data are from four distinct control and mutant mammary gland protein extracts at P18 and L1. ${ }^{*} \mathrm{p}=0.029$ (P18), ${ }^{*} \mathrm{p}=0.048(\mathrm{~L} 1)$

(B) Western blots for RAB5, RAB8, RAB11 and their actin loading controls (left panels). The samples are the same than those shown in (A). The related quantifications shown on the right panels did not reveal any significant differences between control and mutant samples.

(C) qPCR analysis of Rab6a, Rab6a' and Rab6b mRNA expression in mammary cells derived from control and mutant glands at L1. qPCR values were normalized on Gapdh. Data are the mean \pm SEM of 4 separate cell preparations. ns, not significant. ${ }^{*} \mathrm{p}=0.001$ $($ Rab6a $),{ }^{*} \mathrm{p}=0.005($ Rab6a')

Figure 6. Decreased STAT5 activation in Rab6a-deficient mammary glands and RAB6A-depleted T47-D cells

(A)Left panels: western blots for pSTAT5, total STAT5 and actin performed on three distinct control and mutant mammary gland protein extracts at P18 and L1. Right panels: related quantification of pSTAT5/STAT5 amounts (mean \pm SEM). ${ }^{*} p=0.024$ $(\mathrm{P} 18),{ }^{*} \mathrm{p}=0.045(\mathrm{~L} 1)$

(B) Left panel: Western blots for pSTAT5, total STAT5, RAB6 and Actin performed with T47-D cell lysates. SiCtrl and SiRAB6A cells were stimulated with PRL for 5, 15 and 45 min. Right panel: quantification of pSTAT5/STAT5 amount at each time point. Data are shown as mean \pm SEM of 4 separate siRNA assays. ${ }^{*} p<0.05$

(C)Left panel: Western blots for PRLR and actin performed with the same T47-D cell lysates than in (B). Right panel: quantifications of PRLR amount normalized on actin at each time point. Data are shown as mean \pm SEM of 3 separate siRNA assays. $* \mathrm{p}<0.05$

(D) Immunolocalization of PRLR in SiCtrl and SiRAB6A T47-D cells. Enlarged areas of cells double-stained for PRLR and RAB6 are shown on the right. Bars, 30 $\mu \mathrm{m}$ (left), $10 \mu \mathrm{m}$ (right). 
Fig.1

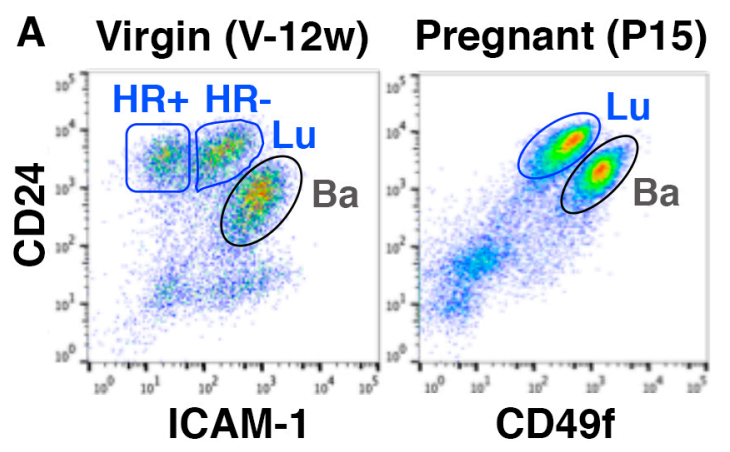

C mRNA expression level
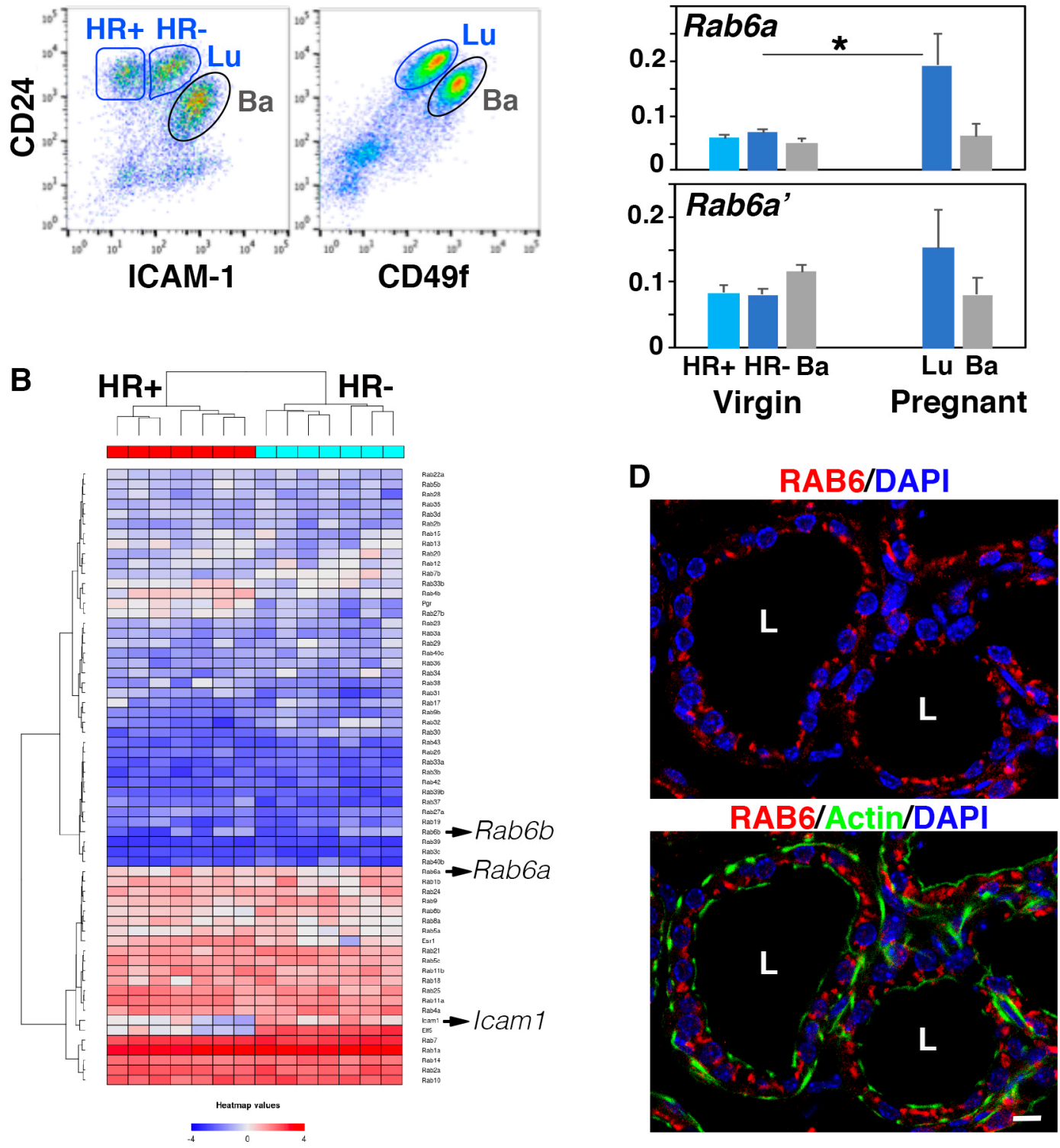
A Ctrl (P18)

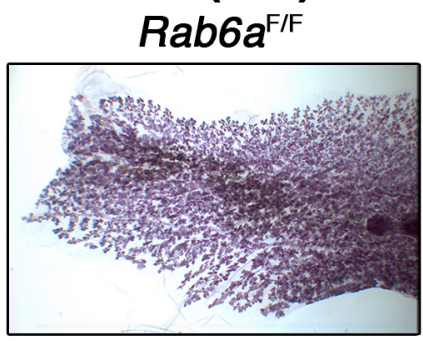

\section{B Ctrl}

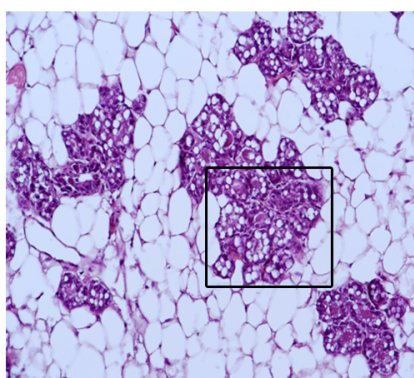

C
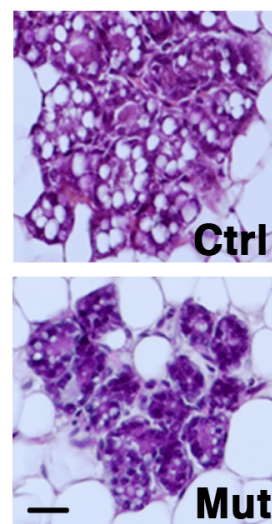

Alveolar size distribution

(\%)

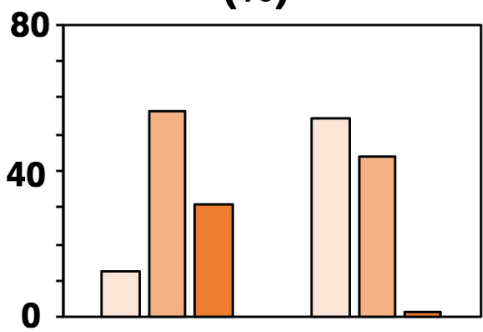

Ctrl

Mut

$\square<1000 \quad \square$ 1000-2000

$\square>2000$

Mut

D

\section{Ki67/SMADAPI}
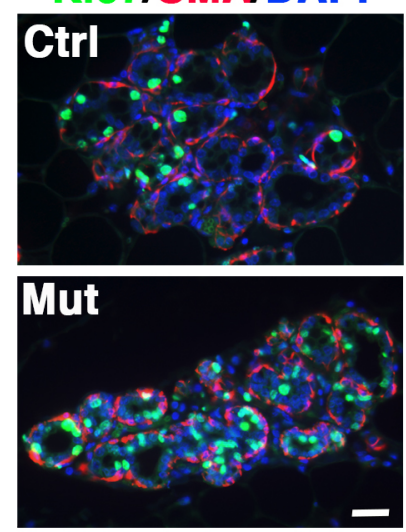

E

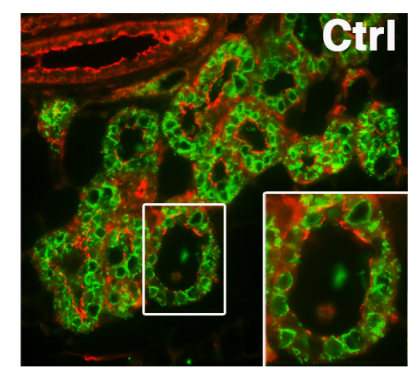

Adipophilin/ZO-1

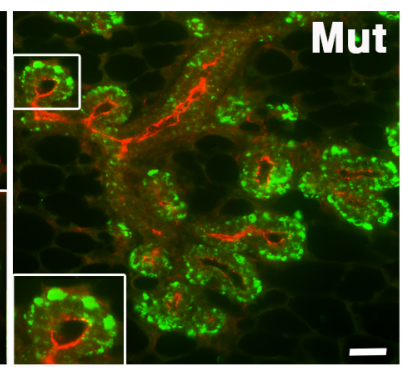

$F$

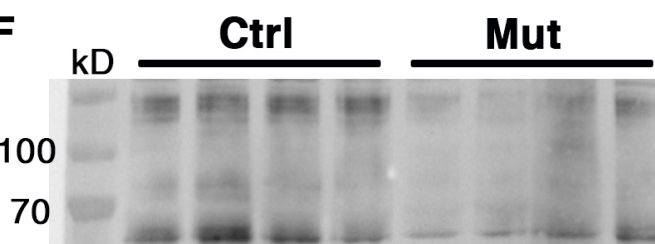

55

35

25

10

G $\beta$-casein/DAPI
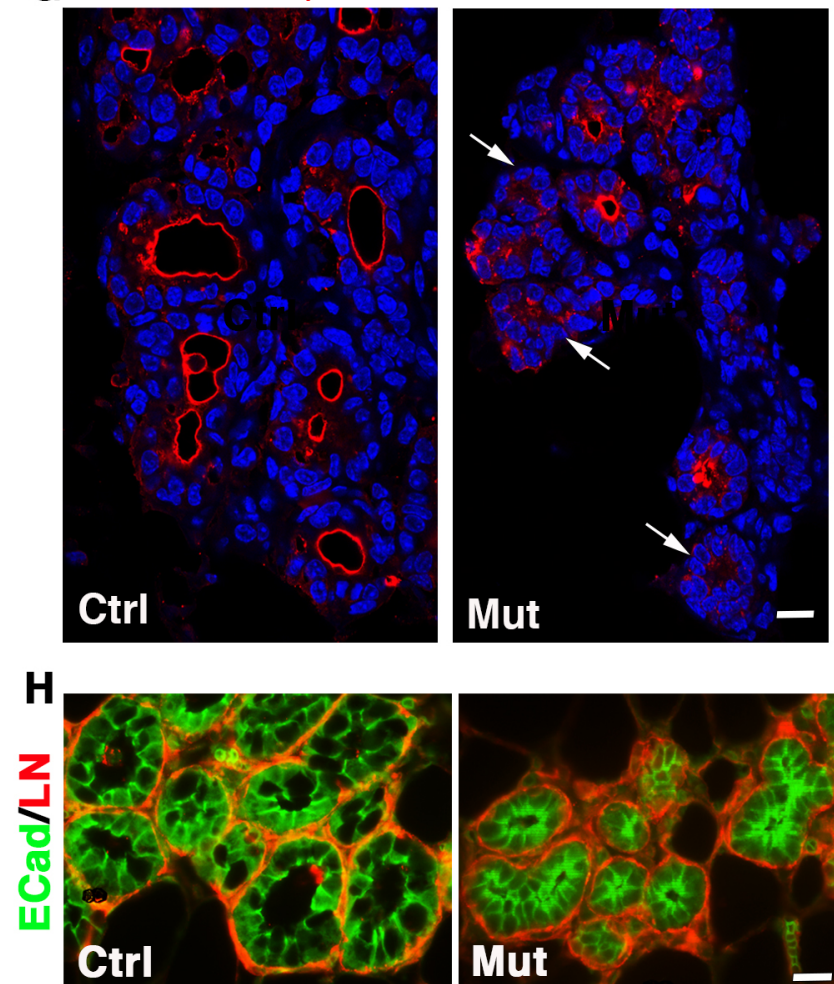

Cas WAP $\alpha$ Lac RAB6 Actin

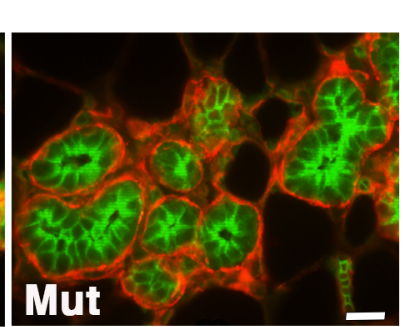


Fig. 3

A Ctrl (L1) Rab6a $a^{\mathrm{F} / \mathrm{F}}$

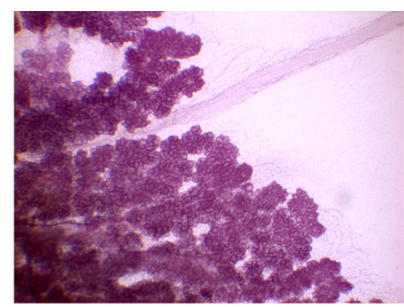

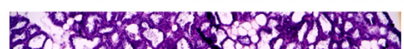
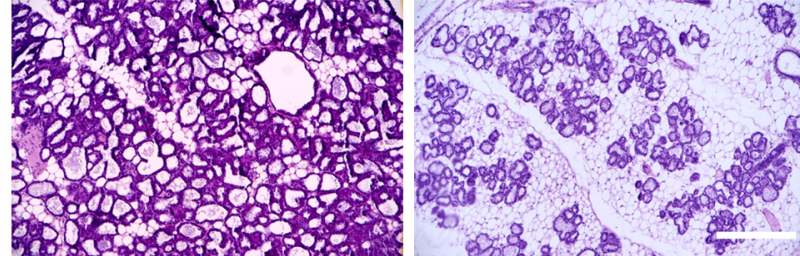

- ososer son 5800
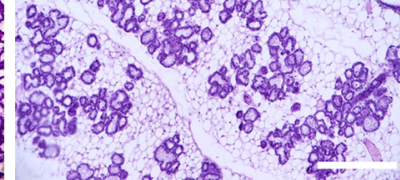

C
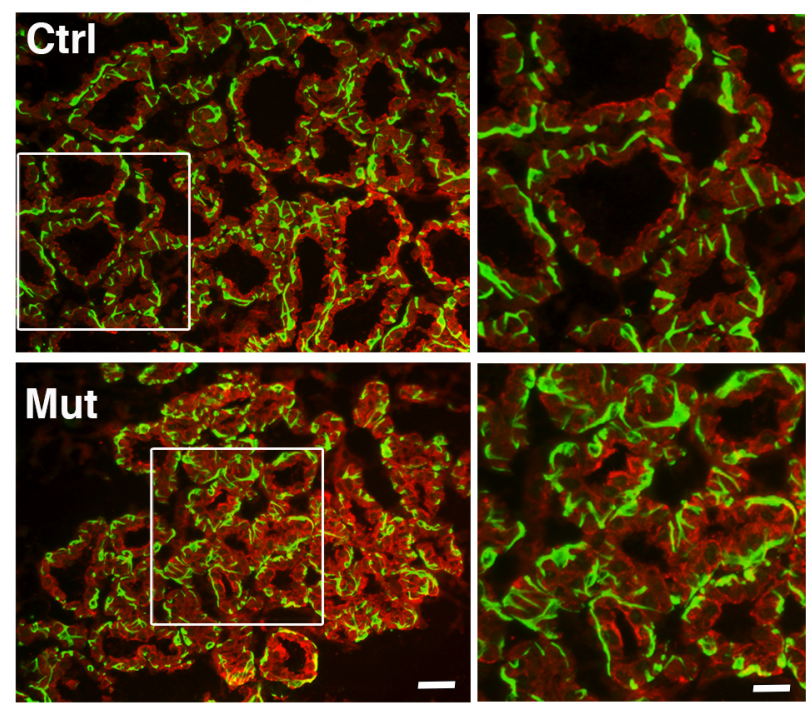

B Actin/RAB6/DAPI
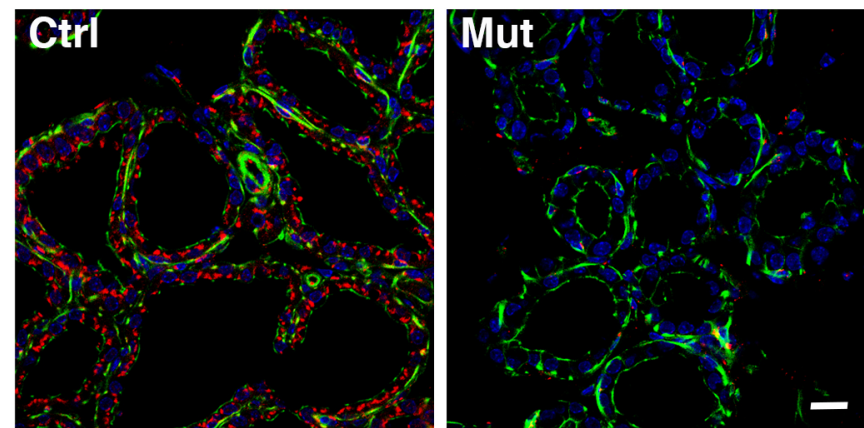

GM130/DAPI

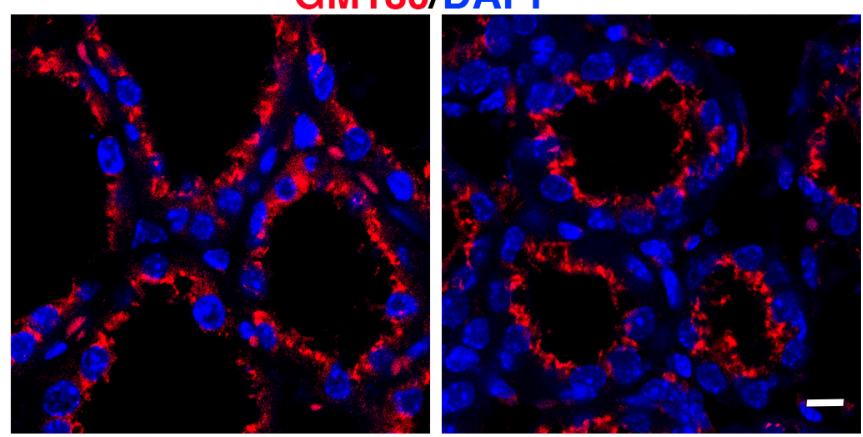

D

LN/DAPI

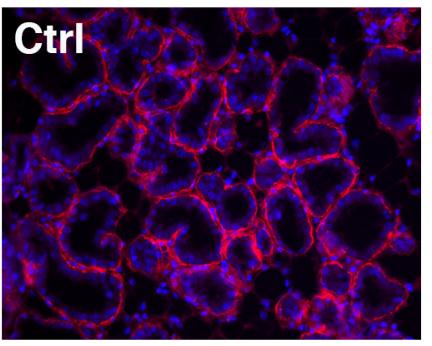

Mut

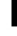

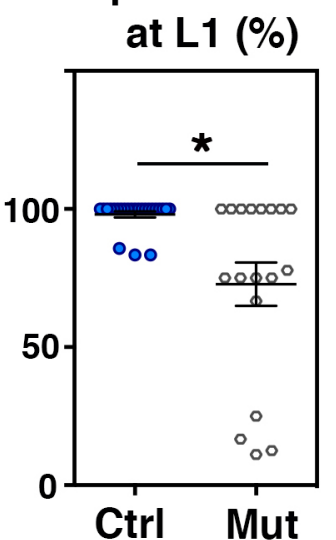

TUNEL + cell number
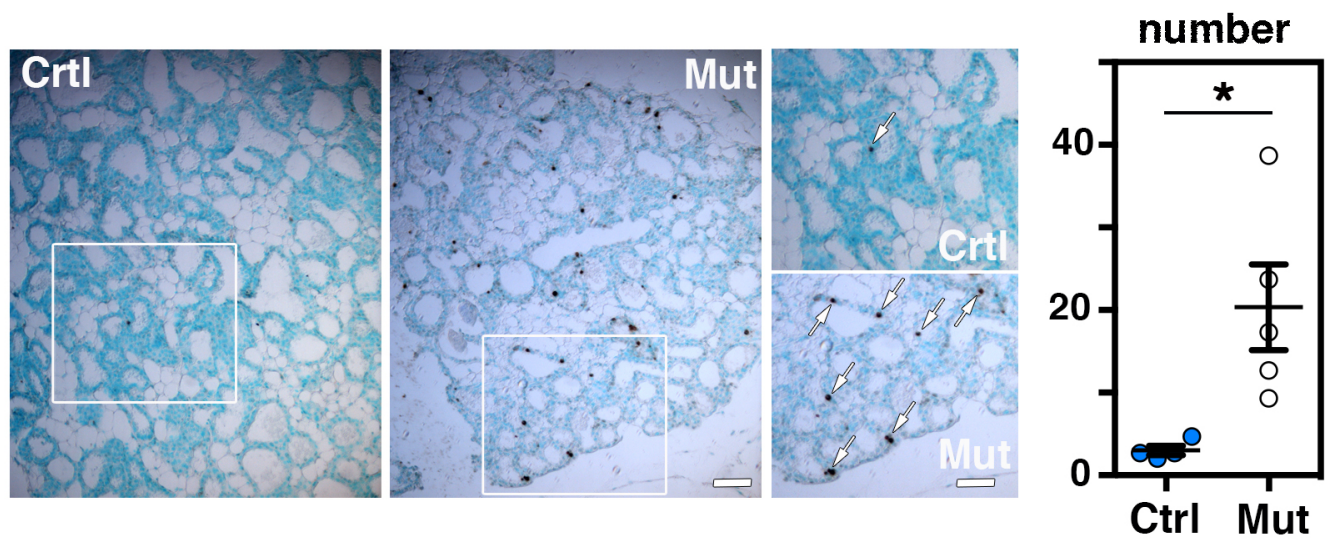
Fig. 4

A Adipophilin/DAPI
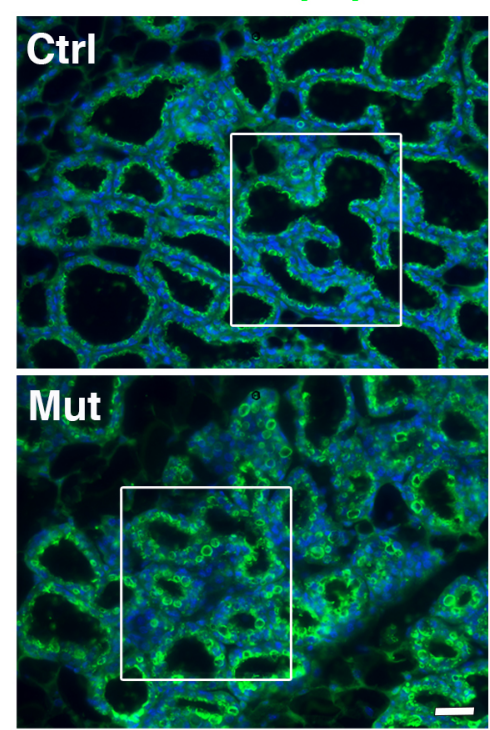

B
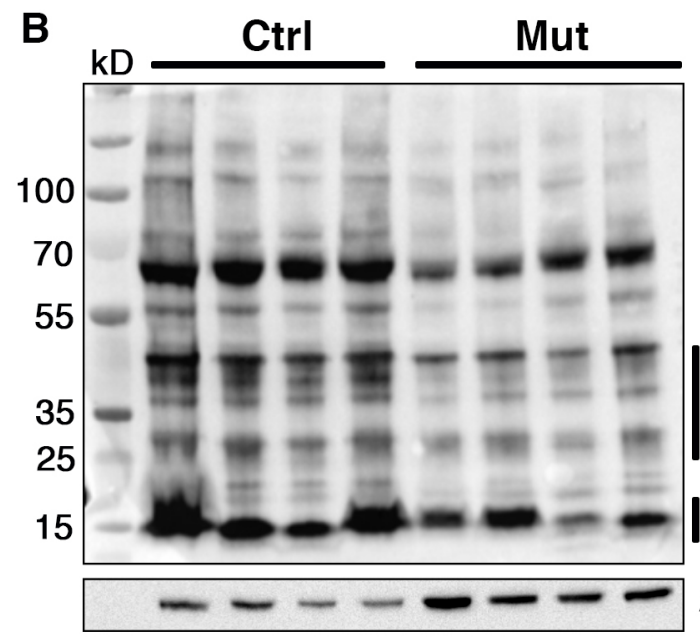

Cas

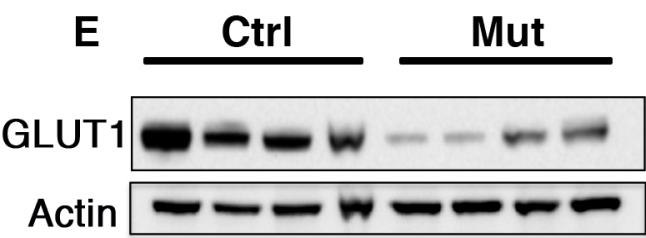

C
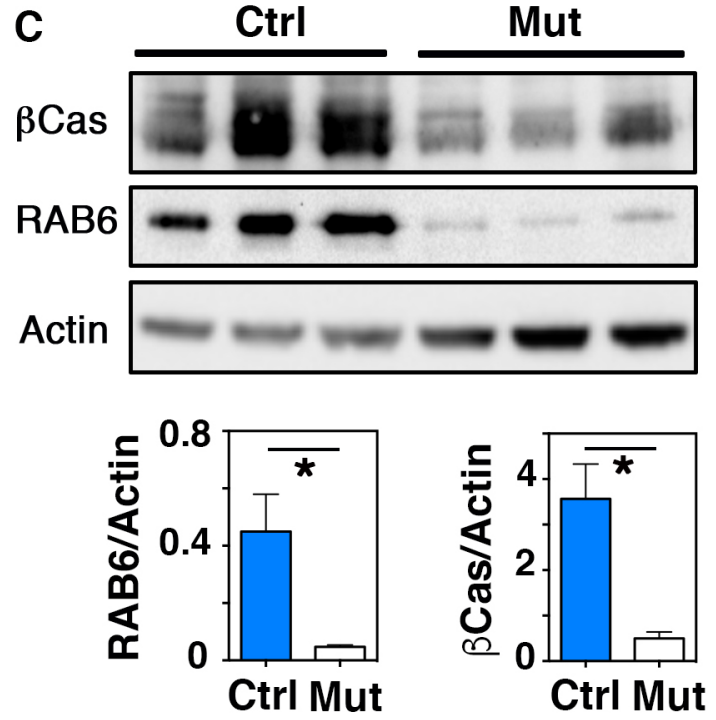

WAP
$\alpha$ Lac

F

GLUT1/DAPI

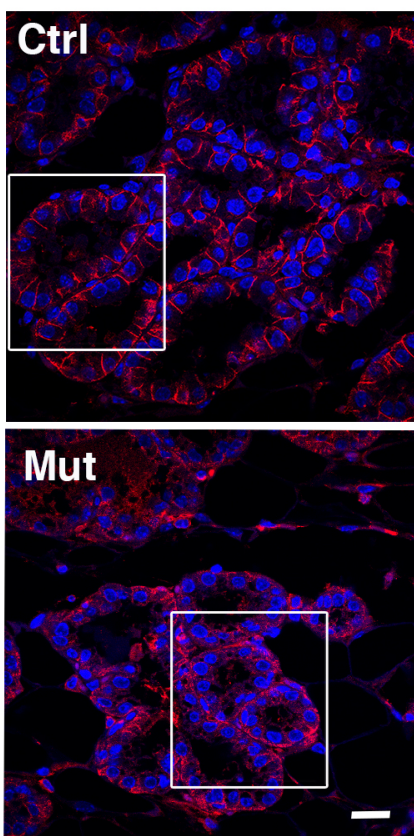

D $\beta$-casein/DAPI
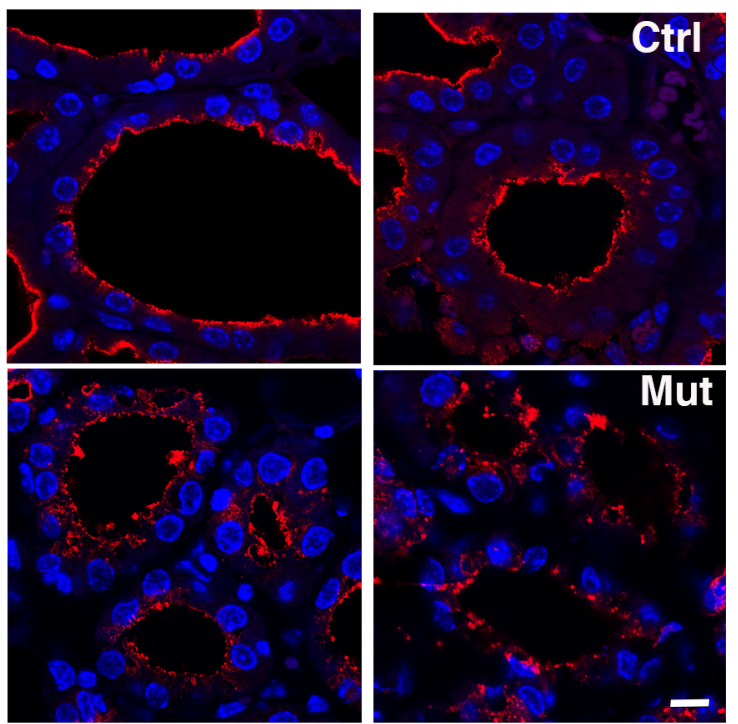

Mut

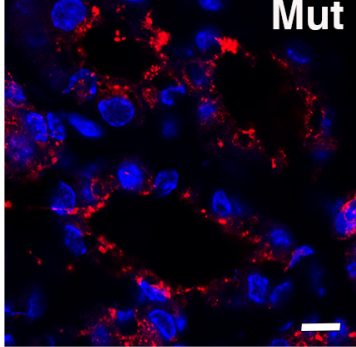

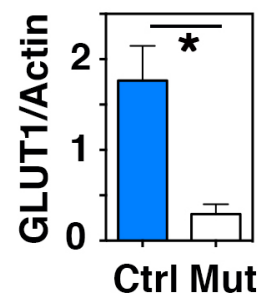

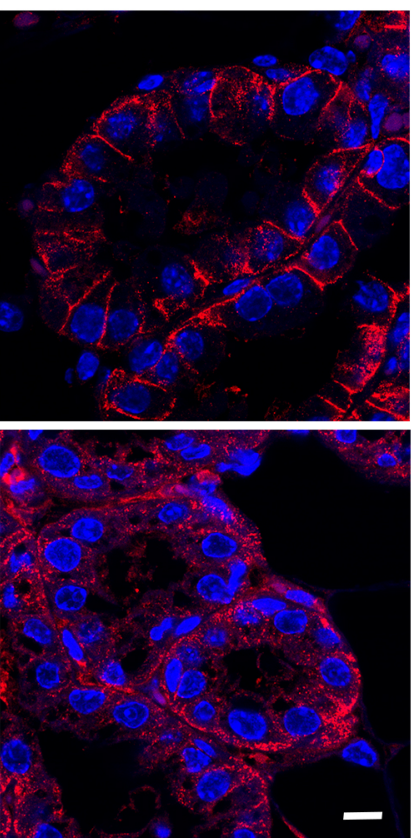


Fig.5
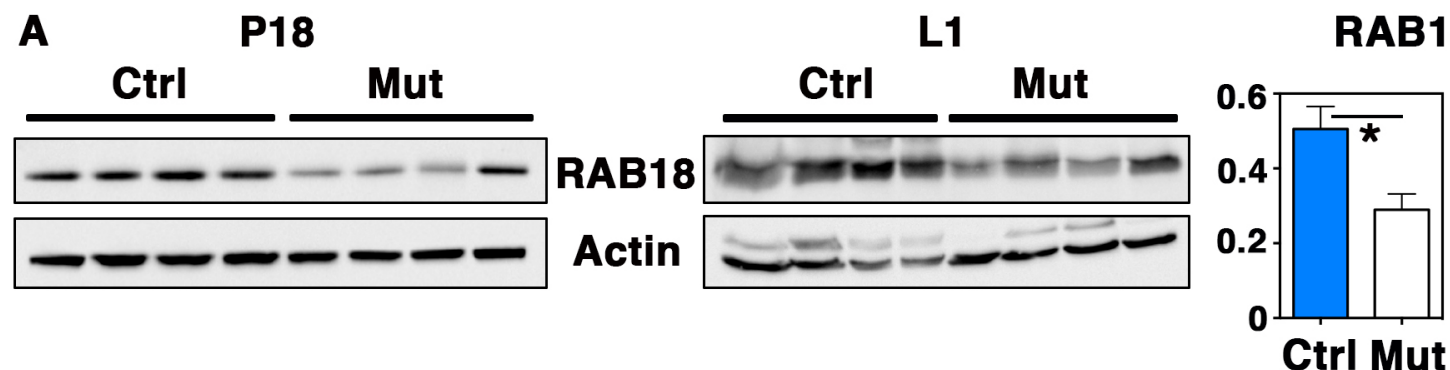

RAB18/Actin

P18

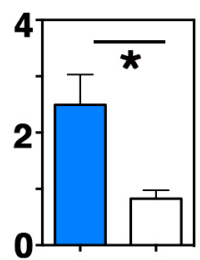

Ctrl Mut
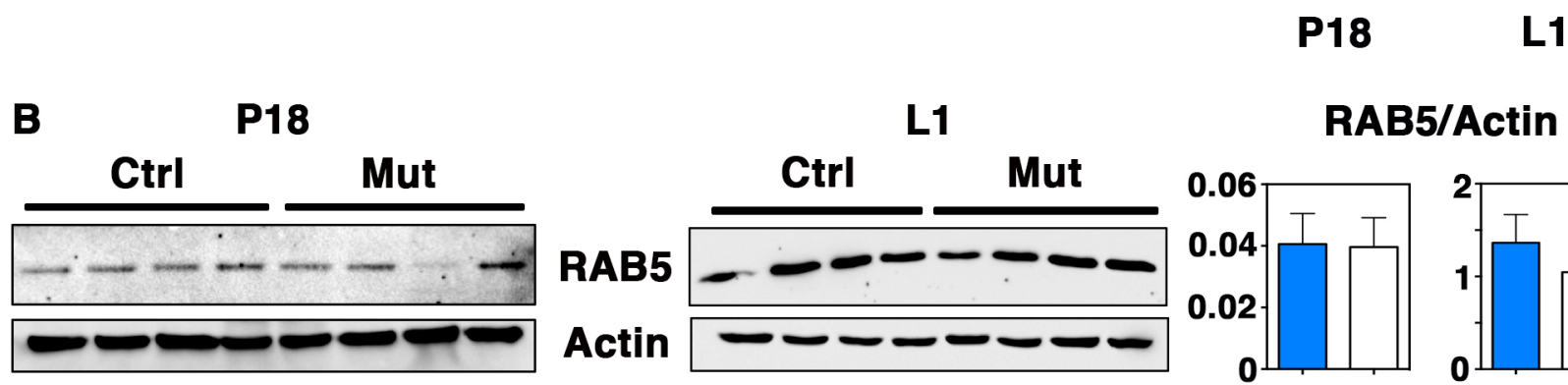

RAB5/Actin

\section{RAB8/Actin}

RAB8

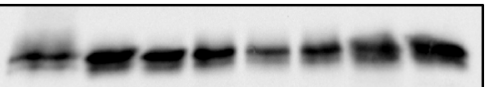

Actin
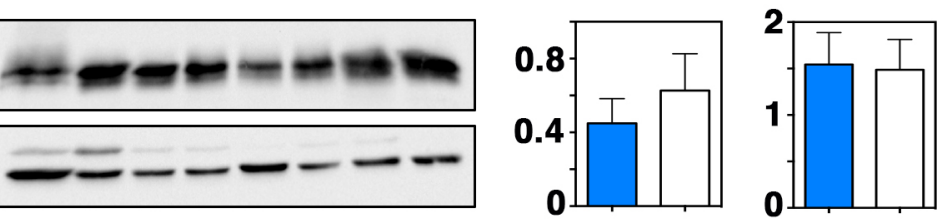

RAB11/Actin
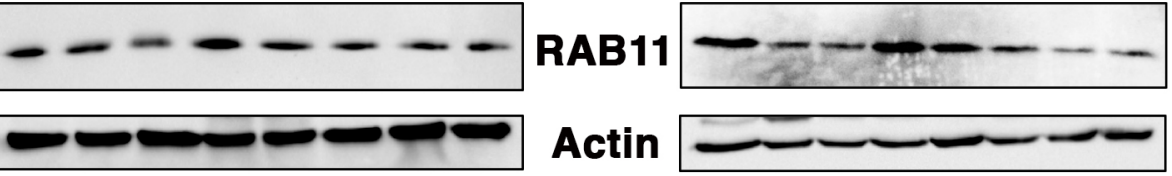

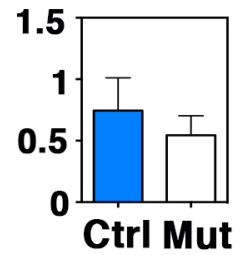

P18

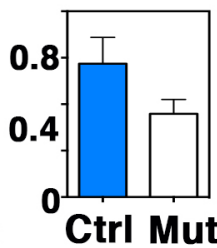

L1

C Expression level (L1)

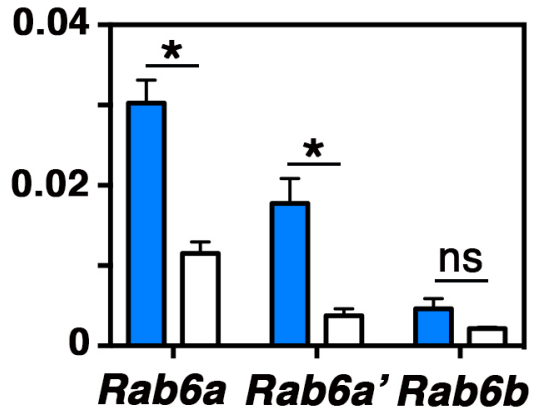




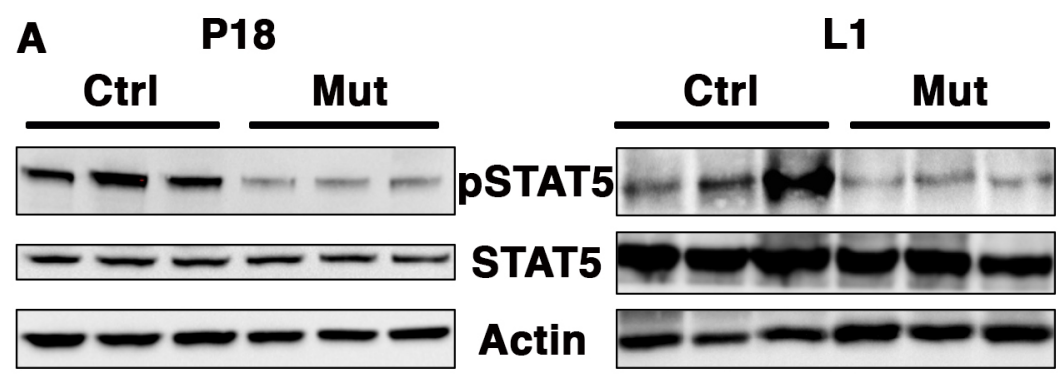

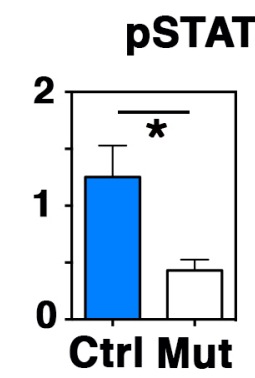

P18

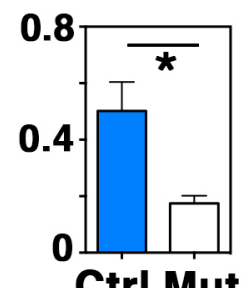

L1

B

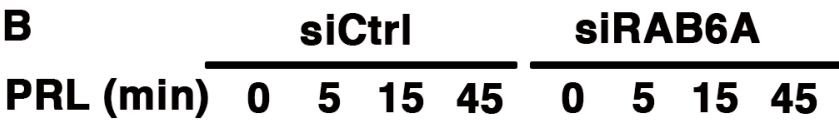
PSTAT5 - - - -

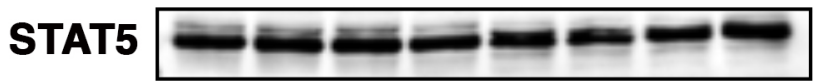

RAB6

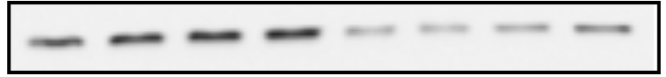

Actin

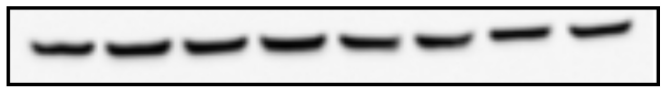

C

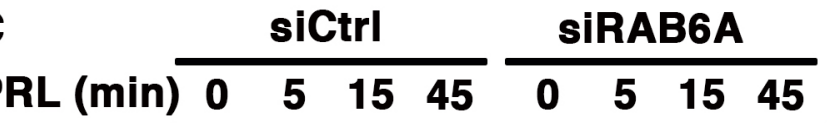
PRLR

Actin

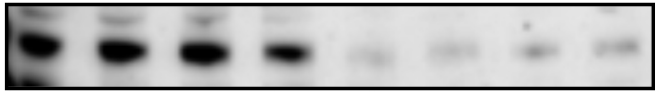

D

PRLR/DAPI

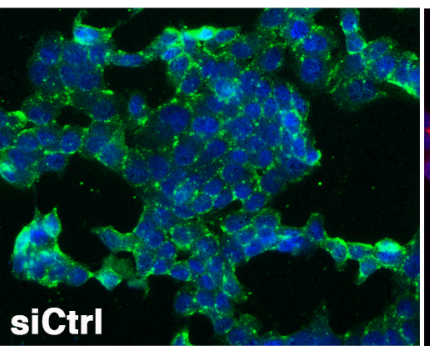

RAB6/DAPI

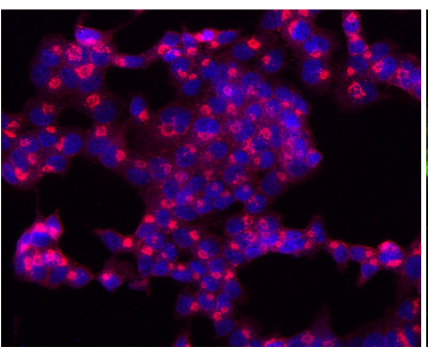

PSTAT5/STAT5
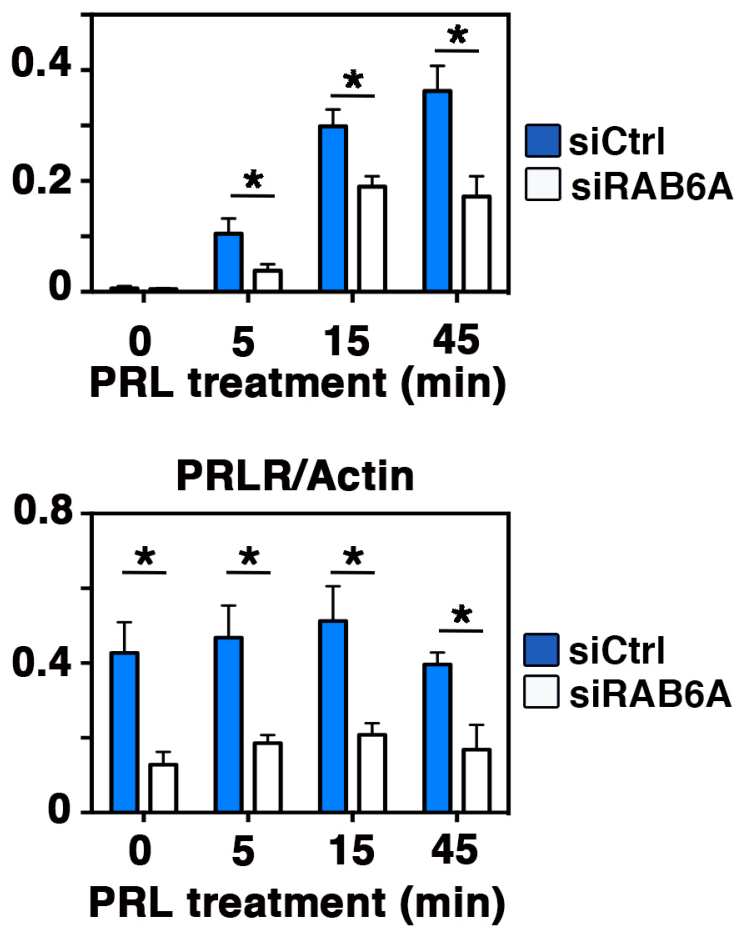

PRLR/RAB6

PRLR/RAB6

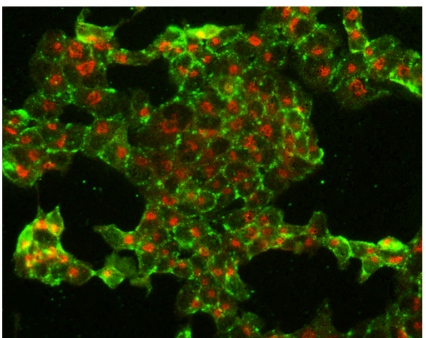

